\title{
THE EFFECTIVENESS OF MILESTONE VERSUS DURATION PROJECTS IN A UNIVERSITY
} ENVIRONMENT

\author{
A Thesis Presented to \\ The Faculty of California Polytechnic State University, \\ San Luis Obispo
}

\author{
In Partial Fulfillment \\ of the Requirements for the Degree \\ Master of Science in Industrial Engineering \\ by \\ Nicholas James Mehas \\ June 2011
}


(C) 2011

Nicholas James Mehas

ALL RIGHTS RESERVED 


\section{COMMITTEE MEMBERSHIP}

TITLE:

AUTHOR:

DATE SUBMITTED:

COMMITTEE CHAIR:

COMMITTEE MEMBER:

COMMITTEE MEMBER:
The Effectiveness of Milestone versus Duration Projects in a University Environment

Nicholas James Mehas

June 2011

Dr. Roya Javadpour

Dr. Reza Pouraghabagher

Dr. Lizabeth Schlemer 


\begin{abstract}
The Effectiveness of Milestone versus Duration Projects in a University Environment Nicholas James Mehas
\end{abstract}

The Critical Path and Critical Chain project management methodologies have different and unique characteristics; both methods are used by project managers to manage projects. This research develops and implements two methodologies, milestones (critical path) versus duration (modified critical chain), in a university environment. The implementation of the two methods allows for the comparison of the effectiveness of both styles. The intent is to determine if there is a significant difference in the project management methodologies in a university setting. The design of both projects allows for easy implementation and the ability to easily record determined measureable statistics. 


\section{ACKNOWLEDGMENTS}

I would like to thank my thesis advisor, Dr. Roya Javadpour, for her time and continuous guidance throughout this process. I would also like to thank Dr. Reza Pouraghabagher and Dr. Lizabeth Schlemer for their suggestions and constructive input which helped improve this thesis. I would like to thank Dr. Tao Yang for allowing me to conduct this experiment in his class.

Finally, I am extremely grateful and blessed to have such a supportive and understanding family and group of friends. I would like to thank both my parents for providing me with the means to pursue my education; my sister and grandparents for their unconditional support. 


\section{Table of Contents}

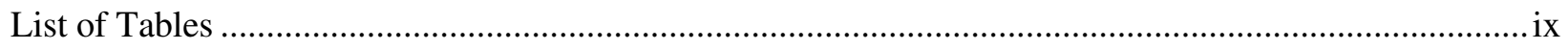

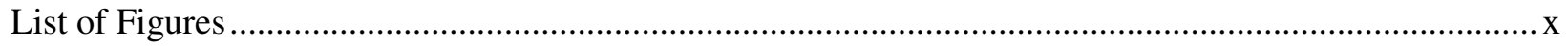

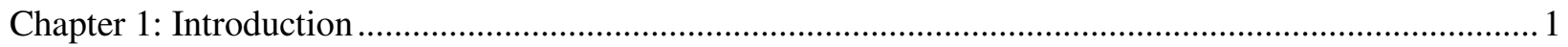

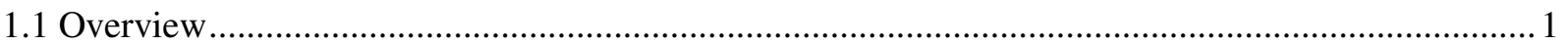

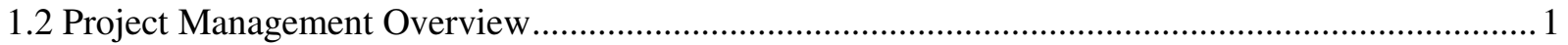

1.3 Critical Path Project Management Overview.............................................................................2

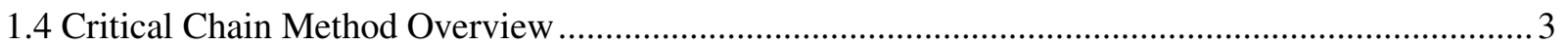

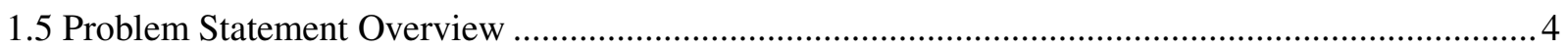

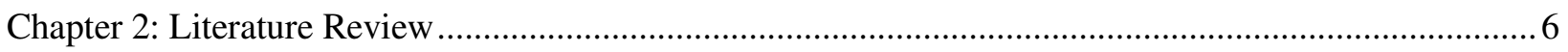

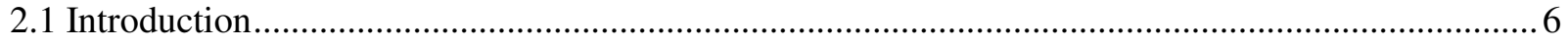

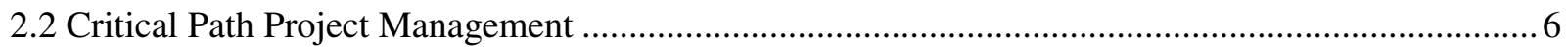

2.3 Critical Chain Project Management ……...................................................................................

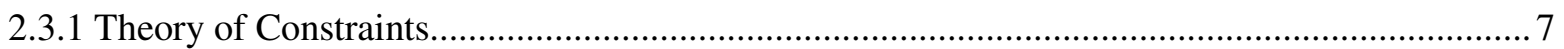

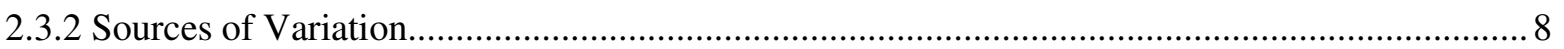

2.3.3 Statistical Laws Governing Common Cause Variation......................................................... 9

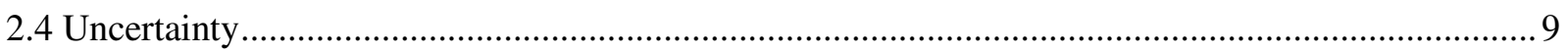

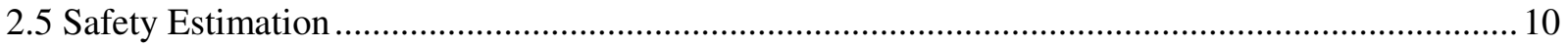

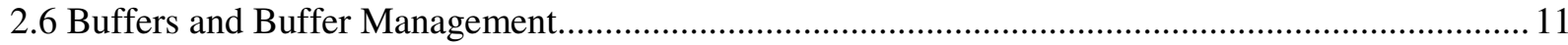

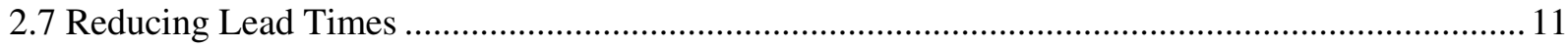

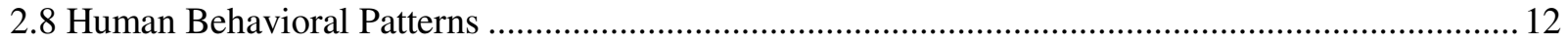

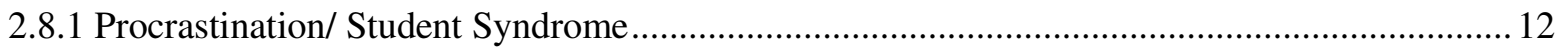

2.8.2 Parkinson's Law and Failure to report early completions ..................................................... 13

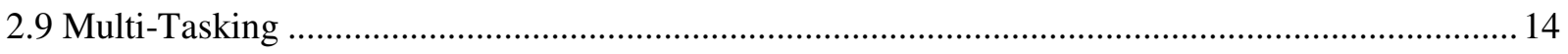

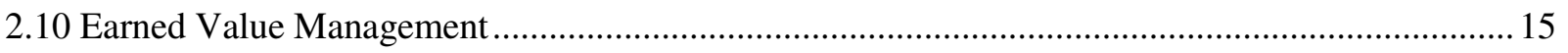

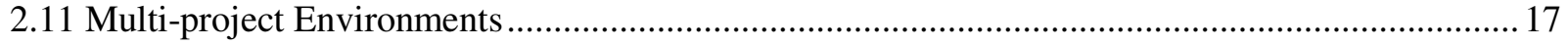

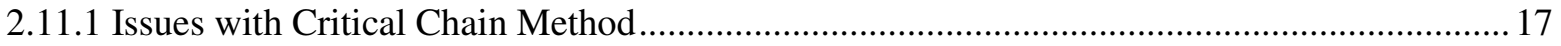

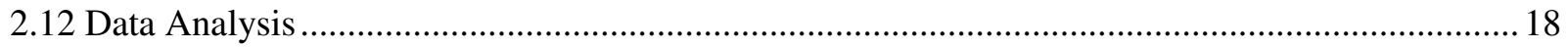

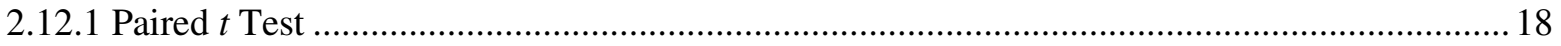

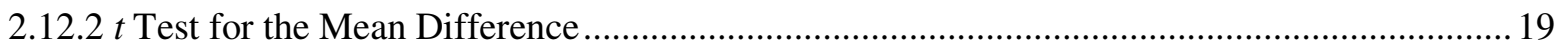

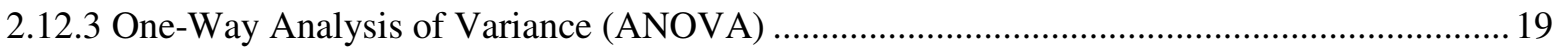

2.12.4 The One-Way ANOVA F Test Statistic......................................................................... 19

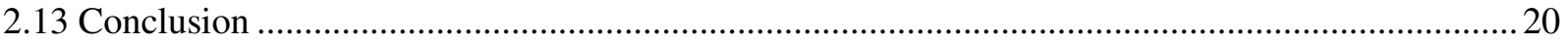




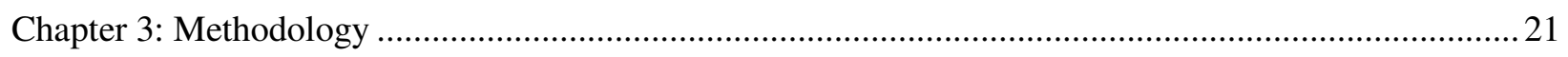

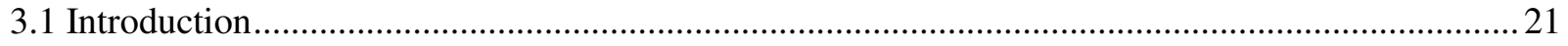

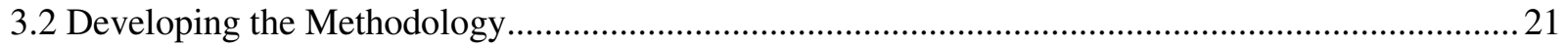

3.2.1 Total Time

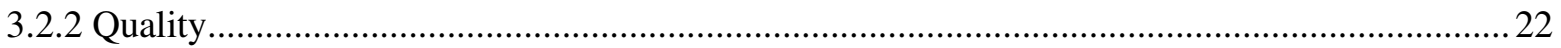

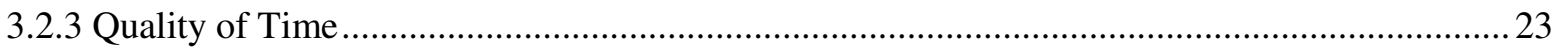

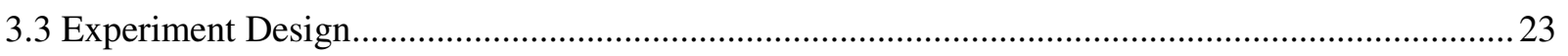

3.3.1 Milestone Project Management Model ............................................................................... 24

3.3.2 Duration Project Management Model................................................................................... 25

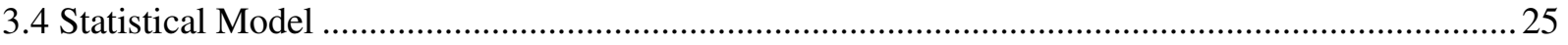

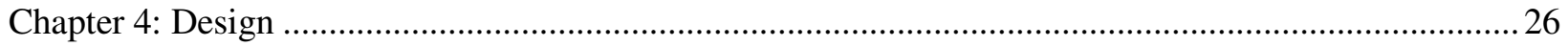

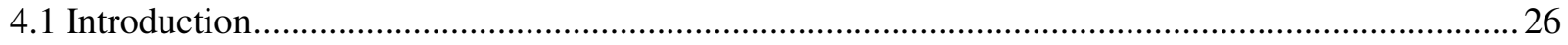

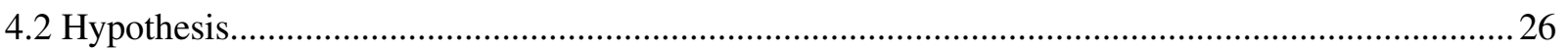

4.2.1 Total Time

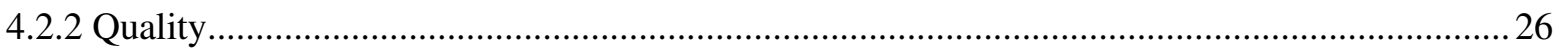

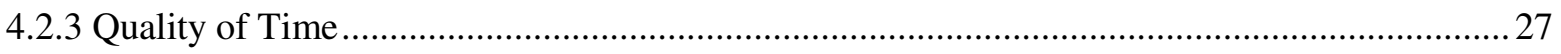

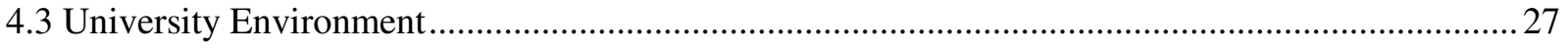

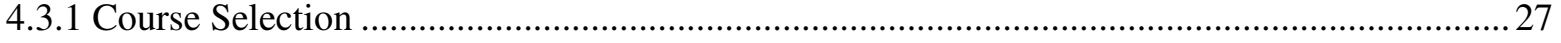

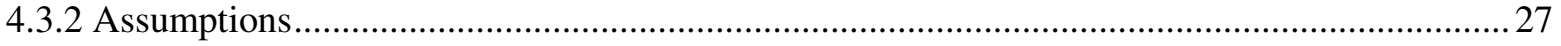

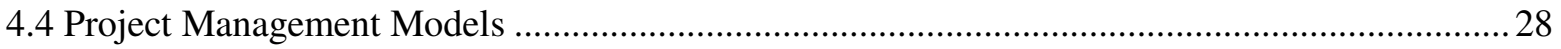

4.4.1 Milestone Project Management Model ….................................................................................... 31

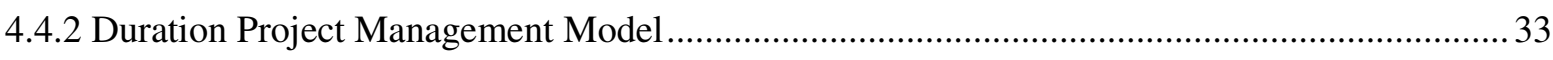

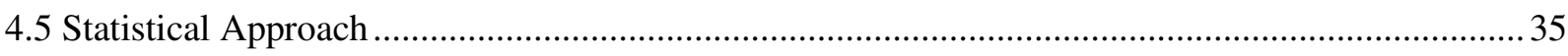

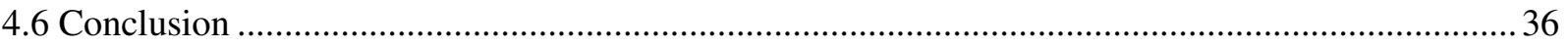

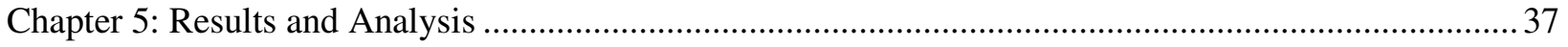

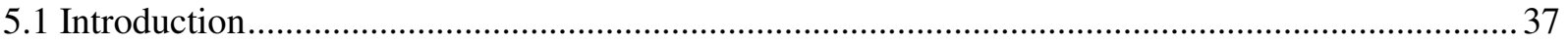

5.2 Results for the Project Management Models ...................................................................................... 37

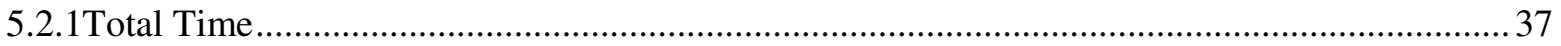

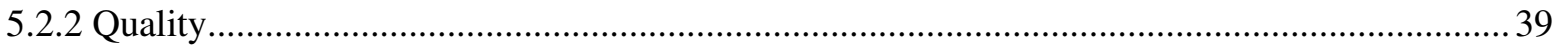

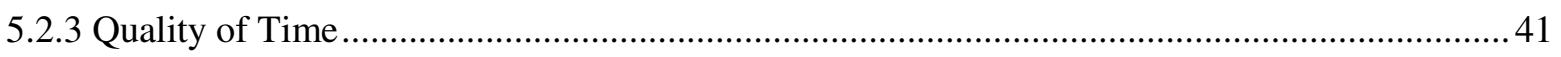

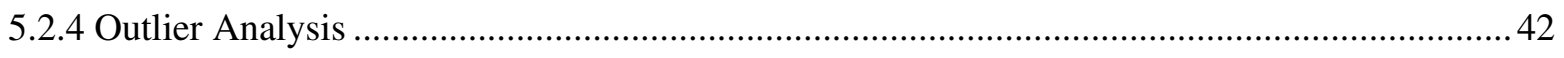

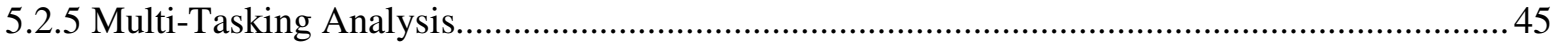

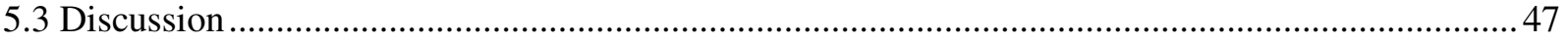




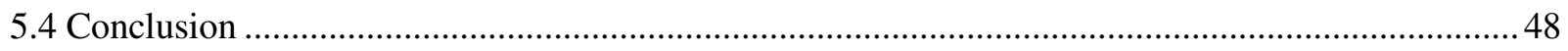

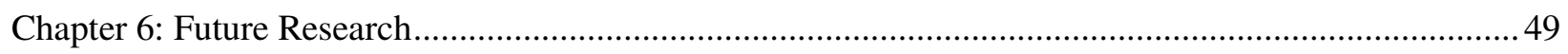

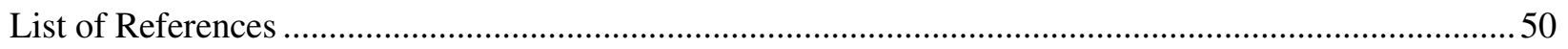

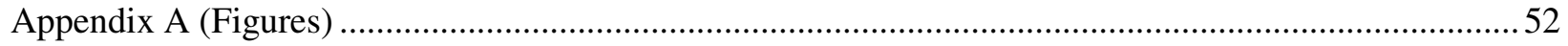

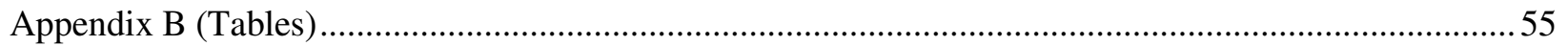




\section{List of Tables}

Table

Page

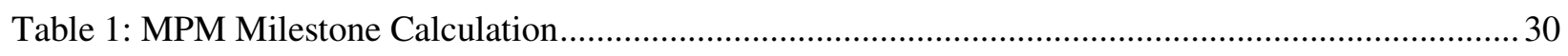

Table 2: Anderson-Darling Test for Normality, P-Value changes ....................................................... 42

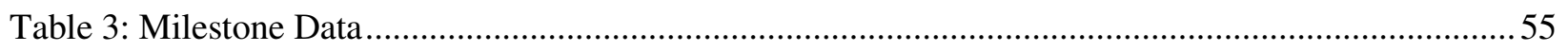

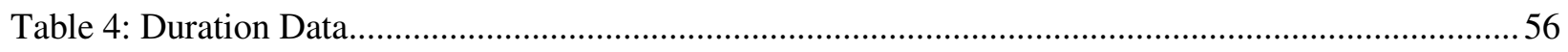

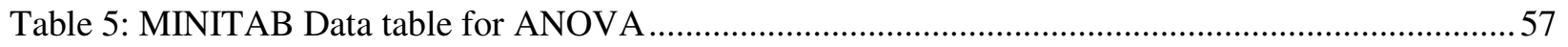

Table 6: $\mu_{\mathrm{D}}$ Data for Total Time, Quality and Quality of Time \& Units .................................................5

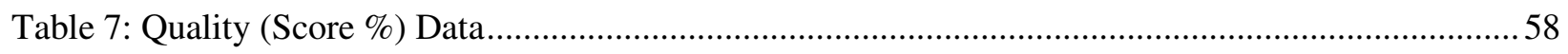




\section{List of Figures}

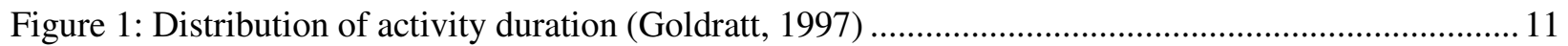

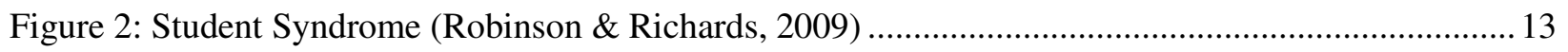

Figure 3: Multitasking Operator (Goldratt, 1997) …........................................................................... 15

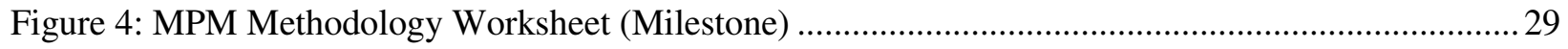

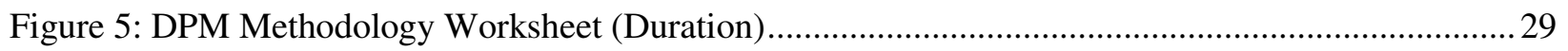

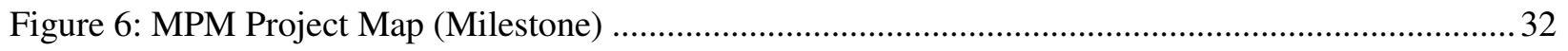

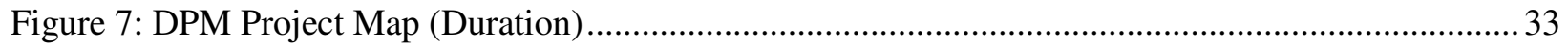

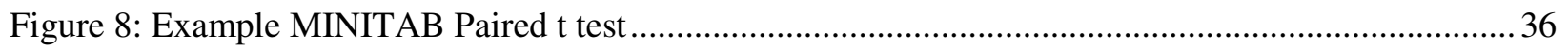

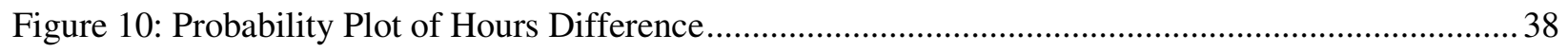

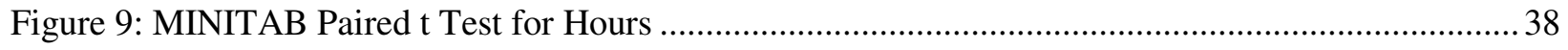

Figure 11: Probability Plot of Score (\%) Difference ……...................................................................... 39

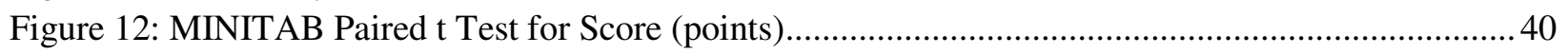

Figure 13: MINITAB Paired t Test for Score (Percentage) ..................................................................... 40

Figure 14: Probability Plot of Score (\%)/ Hr Difference ......................................................................... 41

Figure 15: Wilcoxon Signed Rank Test Score (\%)/ Hr Difference ..........................................................42

Figure 16: Probability Plot of Hours Difference (w/o Outlier) ................................................................ 43

Figure 17: Probability Plot of Score (\%) Difference (w/o Outlier)........................................................... 43

Figure 18: Probability Plot of Score (\%)/ Hr Difference (w/o Outlier) ..................................................... 44

Figure 19: T and P Values for Hours, Score and Score/ Hrs (w/o Outlier) ............................................. 44

Figure 20: ANOVA for Hours vs. Unit, Project Method ........................................................................ 45

Figure 21: ANOVA for Score (\%) vs. Unit, Project Method................................................................... 46

Figure 22: ANOVA for Score (\%)/ Hrs vs. Unit, Project Method........................................................... 46

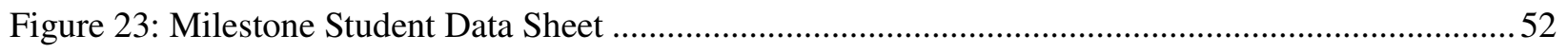

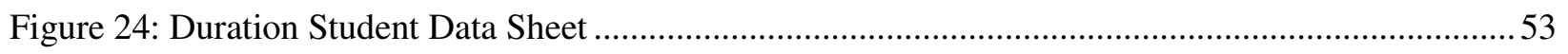

Figure 25: Paired t Test Hours (w/o Outlier), Total Time ....................................................................5

Figure 26: Paired t Test Score (\%) (w/o Outlier). Quality .......................................................................5 54

Figure 27: Paired t Test Score (\%)/ Hr (w/o Outlier), Quality of Time ....................................................54 


\section{Chapter 1: Introduction}

\subsection{Overview}

Organizations assign project managers to lead teams of support personnel in an effort to make project development and implementation as efficient and cost effective as possible. The personnel of these teams consist of people from all divisions of the company: marketing, sales, engineering, manufacturing and so forth. They are responsible for the completion of the project while meeting time and cost constraints. Meeting these project requirements can create severe logistical, resource and schedule conflicts. In order to combat these possible problems several project management techniques have been developed: Critical Path Project Management (CPPM) and Critical Chain Project Management. Within each of the aforementioned techniques there exists the unique process of scheduling milestones.

\subsection{Project Management Overview}

Project Management involves "planning, organizing, and managing resources" to achieve the goals and objectives of the project as well as meet the deadline (Robinson \& Richards, 2009). The expectations associated with project management include "making and keeping commitments under conditions of moderate to extreme uncertainty accompanied by significant levels of complexity and interdependencies" (Robinson \& Richards, 2009). The main goal for management teams is to implement the project(s) within the given triple constraints: budget, time and scope (Lechler et al., 2005, Robinson \& Richards, 2009). In order to achieve this goal two types of approaches to managing projects are used: Critical Path Project Management and Critical Chain Project Management. The two approaches have some similarities, but also have fundamental differences in their goals, focus of attention, uncertainty, resource management, and behavioral issues (Lechler et al., 2005). The following are the main differences between the two methodologies (Cui, 2010):

- The critical path considers the precedence and not the resources. 
- Critical Chain Project Management institutes resource buffer management.

The critical chain is the longest path which considers both the precedence and resource dependence (Cui, 2010). If the required resources are available in unlimited quantities then the critical chain is the same as the critical path (Cui, 2010).

\subsection{Critical Path Project Management Overview}

The Critical Path is defined to be the sequence of activities which determine the earliest completion date of a project; is the longest path through the project (Project Management Institute (PMI) 2008). This path or sequence of activities must adhere to the set schedule and any delay in the sequence will result in an overall project delay. PMBOK defines Critical Path Project Management as a technique used to determine the project duration by analyzing which sequence of activities have the least amount of flexibility or float (Project Management Institute (PMI), 1996).

The goal of using the critical path project management is to satisfy the time, costs, and scope constraints as well as minimize the total duration of the project (Lechler et al., 2005). In some cases there are tradeoffs among the constraints; for example in order to meet the projected completion date the scope of the project may be reduced. Reducing the scope does not necessarily diminish the quality of the project or imply that corners are being cut, but rather management eliminates unnecessary processes or steps in order to satisfy the completion date. According to Lechler (2005), CPPM tends to focus more on the performance efficiency of single projects causing management to squarely focus on the activities that make up the critical path. In regards to resource management the CPPM aims to maximize the utilization of all resources in the project (Lechler et al., 2005).

The critical path project management approach uses contingency plans to protect against external events based on risk analysis resulting in tradeoffs between the triple constraints (Lechler et al., 2005). The human aspect, specifically behavioral issues, only intensifies and increases the amount of uncertainty 
in a project. The behavioral issues discussed in this research for the critical path project management method are associated with resources meeting the specified completion dates for milestones.

\subsection{Critical Chain Method Overview}

Critical Chain is defined as the longest sequence of activities through the project network after resolving resource contentions, in other word critical chain is the set of tasks by which the project overall duration is determined (Rezaie, 2009) and for a multi-project environment it means identifying the bottleneck resource(s) that involve most cross-project utilization (Lechler et al., 2005). Critical Chain Project Management technique improves the overall project performance which results in a reduction in both project changes and project cost overruns (Leach, 1999).

In order to achieve aforementioned aspects CCPM modifies project plans, project measurement \& control systems and the behavior of both the project team and support personnel (Leach, 1999). Another tactic in the critical chain project management method is the elimination of resource contention before the project starts, as well as implementation of buffers for project control (Leach, 1999). The following concepts distinguish the critical chain project management model from the critical path project management model (Leach, 1999):

- The critical chain is considered the project constraint rather than critical path; does not change during the project and includes resource dependencies.

- $\quad$ CCPM uses 50\% probable activity times; distributes allowances for uncertainty into buffers at end of project.

- The measurement of buffer levels is used to control the project schedule.

- CCPM promotes team members to report early activity completion times and eliminates multi-tasking among resources/ operators.

Uncertainty is a major contributor to both delays and cost overruns in the project, CCPM techniques are intended to eliminate undesirable behaviors that are associated with scheduled dates and milestones 
within a project plan (Leach, 1999). According to Leach, (1999) critical chain project management "focuses on developing and managing project performance" in order to reduce activity times.

\subsection{Problem Statement Overview}

Goldratt (1997) suggests that the pitfalls or shortcomings of managing a project consist of the following:

1. The only way to protect the whole [project] is by protecting the completion date of each step.

Resulting in:

2. Each step is protected with additional safety or contingency time.

3. Projects suffer from three mechanisms, when combined they waste the safety time.
a. Student syndrome
b. Multi-tasking
c. Delays accumulate and advances do not

Thus the initial step in the thought process, protecting the completion date of each step, is what Goldratt views as the limitation for critical path project management. Goldratt (1997) develops explanations for the three mechanisms that affect the contingency times for the activities in projects. He concludes that implementing the critical chain project management methodology is a more effective way of governing a project than using critical path project management. However, comparisons between the two styles of management have been limited to company project environments and theoretical computer analysis. In addition previous research and comparisons have not compared projects governed by milestones versus those without milestones in the university environment. This research aims at comparing critical path methodology (milestone) versus a modified critical chain approach (without milestones) in a university environment. This allows the same group operators (students) to implement the two contrasting styles on similar projects. 
This research is designed to determine if there is significant difference between critical path and a modified critical chain project management methodologies in the university environment. The objective is to determine if there is a significant difference between the CPPM and a modified CCPM using the following data.

1. The total hours spent on each project

2. The quality of each project

3. The quality of time

The following chapter is intended to explore the two different project management methodologies which will provide the foundation for the development of the experiment. 


\section{Chapter 2: Literature Review}

\subsection{Introduction}

The intended purpose of this chapter is to provide a comprehensible understanding of the critical path and critical chain project management methodologies. The development of each of these management ideologies are further explained throughout this chapter.

\subsection{Critical Path Project Management}

The critical path is the longest route through the project; the main purpose for implementing the critical path project management methodology is to satisfy the three constraints and minimize the lead time.

In many instances the balance between the three constraints is not necessarily equal because of external factors. Project managers make concessions and tradeoffs among the three constraints in order to ensure the success of a project. Satisfying the completion date is important for any project and failure to meet the deadline can lead to increased costs and lost revenue for all parties involved. Uncertainties are inevitable in any project and plans must be made to combat potential problems. The CPPM approach utilizes contingency plans to guard against external events that could negatively alter any of the three constraints. Scenario analysis of the combination of time, cost, and scope allows project managers to determine the most favorable combination of the triple constraints (Lechler et al., 2005). According to Goldratt (1997) the human aspect, specifically behavioral issues, only intensifies and increases the amount of uncertainty in a projects. The behavioral issues discussed in this research for the critical path project management method are associated with resources meeting the specified completion dates for milestones. The affect of human behavior on critical path project management are addressed later in this chapter. 


\subsection{Critical Chain Project Management}

Rezaie (2009) defines critical chain project management as the longest sequence of activities through the project network after resolving resource contentions, more simply critical chain project management is the set of tasks by which the project overall duration is determined. For a multi-project environment, applying critical chain project management, means identifying the bottleneck resource(s) that involve most cross-project utilization (Lechler et al., 2005). The objective of critical chain project management technique is to improve the overall project performance which results in a reduction of both project changes and project cost overruns (Leach L. P., 1999). Critical chain methodology uses three theories to improve overall project performance (Leach L. P., 1999): Theory of Constraints, Common Cause Variation, and Statistical Laws Governing Common Cause Variation.

\subsubsection{Theory of Constraints}

Critical chain project management applies Theory of Constraint (TOC) concepts to project management (Lechler et al., 2005). TOC realizes that systems are obligated to constraints and that the lack of constraints will result in an unrealistic output: increase without bound limits or eventually go to zero (Leach L. P., 1999)." According to Goldratt and Cox there are several focusing steps in TOC: Identify, Exploit, Subordinate and Elevate (Lechler et al., 2005, Leach L. P., 1999).

- Identify the system constraint: In order to manage a system/project to meet the desired results the system's weakest link needs to be identified. The term "link" can refer to the systems "resource or workstation that is the bottleneck".

- Exploit the system constraint: Exploiting the system uses existing resources to improve the system in order to avoid costly delays.

- Subordinate everything else to the system constraint: Distributing excess capacity in nonbottleneck resources to bottleneck resources, which helps reduce the uncertainty in due date performance. 
- Elevate the system constraint: If, after applying the aforementioned steps the overall performance of the system is not improved or does meet the expectations that are desired then the next step is to increase the overall system capacity beginning with the bottleneck. Elevating systems resources includes many techniques: investment in additional resources, investing in IT infrastructure, management training and so forth. Unlike CP, CC distinguishes between critical and non-critical resources.

- If a new constraint as been discovered, repeat the previous steps; don't let inertia become the system constraint.

\subsubsection{Sources of Variation}

The first source of disparity is common cause variation. Common cause variation is inherent in every system and occurs in the performance time of activities; represents uncertainty in the activity. The effects from the capacity of the system cause fluctuations to occur in the activity: common cause variation occurs naturally in nature. Project networks define activities as dependent even if individual activities may be considered and function independent of each other. In a project network the proceeding activity cannot start until the current activity concludes therefore the activities are dependent (Leach L. P., 1999). The use of contingency in each activity accounts for common cause variation. The second source of discrepancy is special cause variation. Unlike common cause variations, special cause variations can be mitigated or avoided through precautions and those are included in the risk management plan.

Both common cause and special cause variations are accounted for in CPPM and CCPM. The difference between the two methodologies is that critical chain project management utilizes the central limit theorem to take advantage of common cause variation whereas critical path project management ignores the variation. Critical chain project management employs "some statistical properties of variances of additive random variables" which results in an earlier completion time than critical path project management. 


\subsubsection{Statistical Laws Governing Common Cause Variation}

Using the statistical method to combine variances reduces contingency of the project activities but still maintains enough to protect the project as a whole (Leach L. P., 1999). The aggregation of contingency reduces overall estimated time for activities (Leach L. P., 1999). This theory is expanded upon further in the safety estimation section.

\subsection{Uncertainty}

Uncertainty exists in every project; the degree to which the uncertainty exists can be determined by the conditions that are present during the execution of the project (Robinson \& Richards, 2009). Elements that increase uncertainty consist of the following, but are not limited to: the number or range of possible outcomes for a given element of the plan, the overall length of the project, the number of different resource types or organizational entities involved in delivering the project, and the level of interdependency that exists between the various activities of the project (Robinson \& Richards, 2009). As these conditions increase or become more and more relevant the capacity to which the management team can determine the overall cost and duration of the project decreases. In order to combat and minimize the uncertainty, contingency plans or safety are incorporated into the project plan.

Contingency plans most usually consist of additional time allotted or an increased budget, which help mitigates the degree of uncertainty. However, contingency plans generally increase a project's original completion date and budget, which contradicts CPPM or CCPM. The pressure exerted by executives and owners to decrease the cost and time of the project causes project managers to disguise contingency plans (Robinson \& Richards, 2009). The concept of embedding safety "in each task or activity to ensure that its chance of completing on time and on budget are reasonably high" is a way that contingency is disguised in project plans (Robinson \& Richards, 2009). The amount of safety added to each step is directly related to the consequences of missing the completion date. Ridding projects of

uncertainty is the desire for every owner or corporation; however Murphy's Law can strike at any time 
and stick around for an unknown amount of time. The aforementioned concept of adding contingency to each individual step is a method that has been used since the inception of CPPM methodology. However, why do projects with contingency steps still fail to meet the proposed completion date? Goldratt (1997) provides and explanation for this phenomenon in which he concludes that human behavior leads to project delays.

\subsection{Safety Estimation}

One of the key tools in combating uncertainty is through the use of safety (contingency) times. Goldratt (1997) suggests that in the CPPM each activity's safety estimation follows the distribution seen in Figure 1, where the estimation uses the 90 percent quartile instead of the 50 percent quartile (Rezaie, 2009). Unlike CPPM, critical chain project management eliminates the "safety times from [individual] activities and adds it up to the overall project (Rezaie, 2009)." Goldratt (1997) discusses the tendency that "people involved in time estimation overestimate the required time so that enough safety time is put into the estimations (Rezaie, 2009)." Yet, even with additional safety, caused by overestimating, project still fail to adhere to the schedule and meet completion dates. According to Goldratt two factors are responsible for the failed completion dates: Student Syndrome and Parkinson Law (Rezaie, 2009). Goldratt's solution to overestimating is to implement $50 \%$ probable estimates. This means that using the .5 or $50 \%$ estimated activity duration instead of the .9 or $90 \%$ estimation will result in lead times that are

significantly shorter (Figure 1). The contingency time that was incorporated into the $90 \%$ estimate is not entirely eliminated because of the existence of contingency time at the end of the critical chain (Rezaie, 2009). 


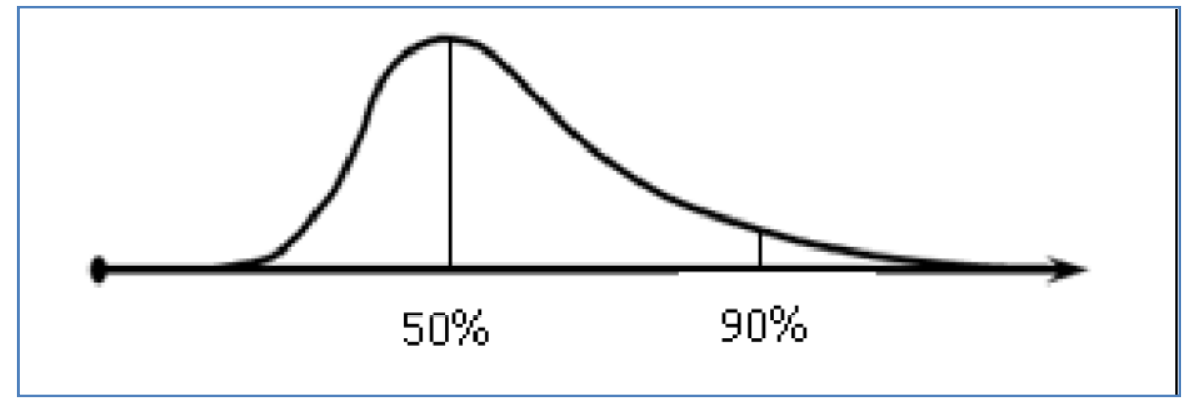

Figure 1: Distribution of activity duration (Goldratt, 1997)

\subsection{Buffers and Buffer Management}

The second tool is buffer management, which occurs after safety times from individual activities have been placed at the end of the project. Buffer management is a monitoring system that allows managers to observe activities that have the potential to cause serious project delays, and it provides a proactive alerting mechanism (Rezaie, 2009). The system also allows management to "monitor the extent to which [the buffers] are penetrated during schedule changes (Zhau et al., 2010). The term buffer management is defined as the process of monitoring buffers and planning and executing recovery actions based upon it is called buffer management (Rezaie, 2009). The buffer management system consists of two types of buffers: the project buffer and the feeding buffer. The project buffer guards the critical chain against uncertainty, absorbing any variation that occurs within critical chain activities. Similar to the project buffer the feeder buffer protects and absorbs any uncertainty that occurs in the non-critical chains. (Rezaie, 2009).

\subsection{Reducing Lead Times}

Mitigating scheduling risk is a key as aspect in project management and will help to eliminate potential problems that cause project delays. These delays often affect the overall lead time which increases the possibility of a postponed completion date and the chances that the project will become over budget. Goldratt (1997) concluded that the elimination of safety time will result in the overall reduction of 
lead time. The concept of eliminating safety time does not imply that the project loses its safety time, but rather each individual step in the project will lose its safety time.

The idea is to eradicate self-fulfilling time estimates for safety and the notion that $5+5=13(6)$. The latter represents two individual steps each with 5 units of safety and resultant total of 13 units: the resultant value includes safety that is added by a manager. The fallacy with this logic is that additional safety given by the manager has just increased the overall lead time of the project by another three units. In order to avoid inflated safety times the individual(s) responsible for scheduling should eliminate safety for individual steps. In order to avoid inflated safety times the individual(s) responsible for scheduling should eliminate safety for individual steps. Instead they should determine how much safety needs to be given to the entirety of the project because not all steps will use their allotted safety time and no one can be sure when Murphy's Law might strike. In addition to shortening the safety times, lead can be reduced through collaboration and negotiation. Goldratt (1997) states that there are two types of projects: one down by vendors and contractors and one done with the resources from the company.

\subsection{Human Behavioral Patterns}

Human behavior tendencies adversely affect project lead times. The following two human behavioral patterns help to explain why projects with contingency embedded in individual steps fail to meet completion dates.

\subsubsection{Procrastination/ Student Syndrome}

The first human behavioral issue is procrastination or student syndrome: waiting until the completion date is near to began work on an activity or process. Another description of student syndrome states "people postpone focusing on their tasks to the latest time they think they can finish them on time (Rezaie, 2009)." This is well documented occurrence in academia, but also occurs in the workplace. The knowledge that additional time, money, or resources have been infused into each individual process or activity influences day-to-day decisions (Robinson \& Richards, 2009). In many cases "the fact that in the 
workplace there are often several other, more urgent work responsibilities to be addressed, it is then understandable that many tasks or activities are only executed when the level of urgency associated with them is sufficiently high to justify the effort required to accomplish them (Robinson \& Richards, 2009)."

Student Syndrome results in the depletion of the embedded contingency, which was originally designed to combat uncertainty causing the completion of the activity to be delayed. Immediately after the schedule start date progress occurs on the activity, but because of other responsibilities progress slows and ceases. Not until the "deadline trigger" does work commence again; at this point the level of urgency is extremely high causing the activity to be completed. However, the lack of progress before the "deadline trigger" resulted in consumption the contingency, thus causing the activity to finish late: Figure 2 below shows an activity versus time chart for student syndrome (Robinson \& Richards, 2009).

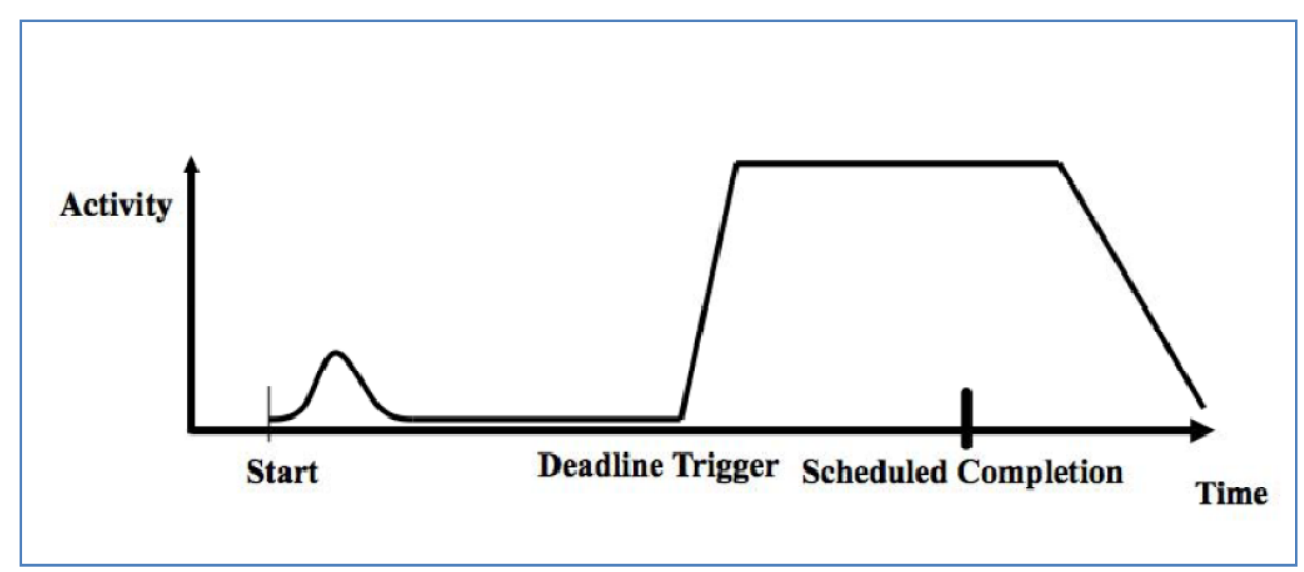

Figure 2: Student Syndrome (Robinson \& Richards, 2009)

\subsubsection{Parkinson's Law and Failure to report early completions}

Parkinson's Law states "the work expands itself to fill additional time." The second human behavioral issue relates to Parkinson's Law and Failure to report early completions; these theories assume that there is unused contingency (Robinson \& Richards, 2009). Most activities are given a good amount of safety in order to protect against any conceivable delay. However, not all the activities will use their 
assigned safety, which results in a surplus of unused contingency that is not reported (Robinson \& Richards, 2009).

Sandbagging is a term used to describe as an action where operator intentionally requests more time and or monetary resources where neither resource is actually required (Robinson \& Richards, 2009). The notion of sandbagging in the work environment is seen as a negative action, thus resources will generally exhaust their allotted time even if the extra time was not needed. There are some cases where the activity is completed, but it is not reported until the contingency is used or the scheduled completion date occurs. The compounding effects of student syndrome combined with Parkinson Law leads to waste of the safety times (Rezaie, 2009).

\subsection{Multi-Tasking}

According to Goldratt (1997) multi-tasking among operators contributes to delayed project completion. For the majority of businesses or corporations having multiple projects occurring simultaneously is not an unusual occurrence. In some scenarios the existence of multiple projects results in resources that are not solely dedicated to a single project (Robinson \& Richards, 2009). Multi-tasking exists because of how difficult it is to successfully plan projects in way that "efficiently balance[s] the load across all resources [in such a way that] all resources are productively engaged during the entire project (Robinson \& Richards, 2009)." The root form of multi-tasking occurs because the demand for a resource's time is needed for several projects, causing the resource to move from project to project without completing the previous task (Goldratt, 1997). If a resource is idle during the project the company incurs the cost of the idle resource, but sometimes this scenario is unavoidable. However, in some instances there are periods of planned downtime, but those resources must remain available if they are suddenly required (Robinson \& Richards, 2009). In order to minimize the cost incurred by idle resources companies have developed a couple solutions (Robinson \& Richards, 2009): 
- Sacrifice availability

- Share resources across multiple projects.

The latter of the two solutions is widely used across almost every type of industry. The belief is that if every resource is at max utilization and all resources are at maximum utilization then company is at its full productive potential (Rizzo, 2006). Contrary to this belief, multi-tasking among resources negatively effects cycle times of project. Below, Figure 3 shows an example of an operator who is multitasking on three components (A, B, \& C) each whose lead time is 10 units (Goldratt, 1997). The operator completes half the component and then begins on the next component. The result is that original lead time has now increased substantially for each component from 20 units to 10 units.

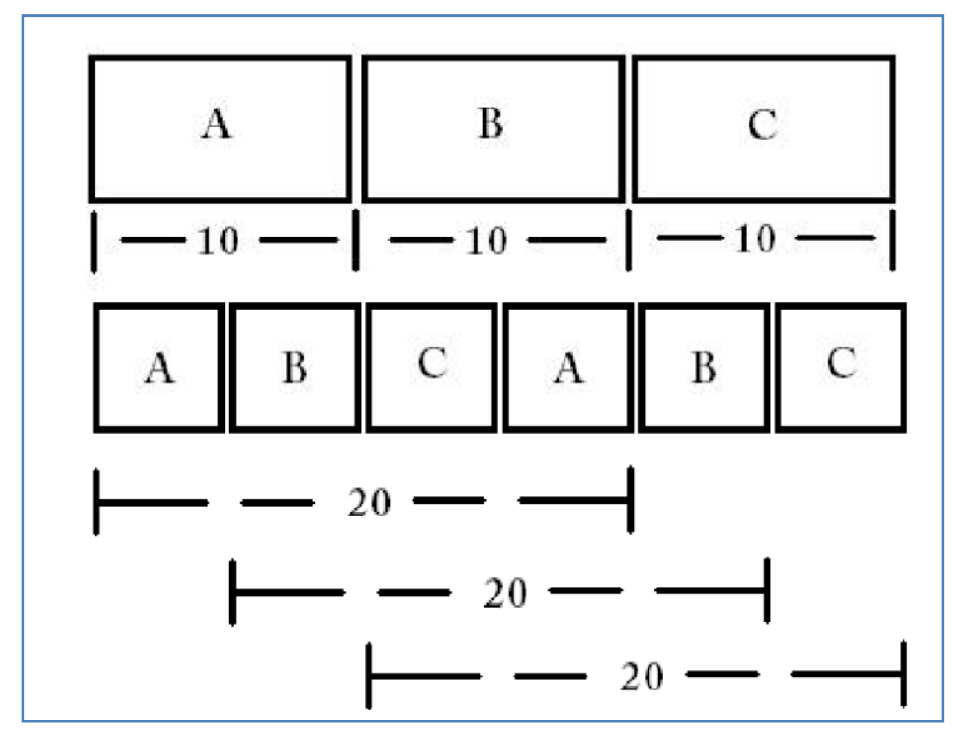

Figure 3: Multitasking Operator (Goldratt, 1997)

\subsection{Earned Value Management}

Earned value management $(\mathrm{EVM})$ is defined as a management methodology for integrating scope, schedule, and resources, and for objectively measuring project performance and progress. Performance is measured by determining the budgeted cost of work performed (Earned Value, EV) and comparing it to the actual cost of work performed (Project Management Institute (PMI), 2008). Earned Value is the value of work performed expressed in terms of the approved budget assigned to that work for 
a schedule activity or work breakdown structure component. EVM is referred to as the budgeted cost of work performance (Project Management Institute (PMI), 2008).

Earned Value Management (EVM) is "tool intended to expose a program's or project's cost, schedule, and technical performance (Cerveny \& Galup, 2002)" in an objective manner (Naeni, 2010). The Project Management Institute defines Earned Value Management as the combination of three measurements: technical performance, schedule performance, and cost performance (PMI 2005). The technical performance is the accomplishment of planned work, schedule performance is whether or not the project is behind/ahead of schedule, and cost performance is whether or not the project is under/over budget (PMI 2005). Earned value management is able to calculate the following (Naeni, 2010):

- Cost and time performance indices of a project,

- Estimation the completion cost

- Completion time of a project

- Performance and progress of a project

EVM is able to calculate the aforementioned value by comparing planned value and actual costs of activities to their corresponding earned values (Naeni, 2010). It also provides management support in forecasting the final cost of a project or system (Lipke, 2009). Above all EVM is designed to provide early warning indicators or performance problems within the system (PMI 2001).

Although an activities' progress involved in a project may be uncertain, the progress is considered deterministic with EVM techniques (Naeni, 2010). In order to measure and manage the cost and the schedule reserves in projects, cost and schedule ratios were developed by (Lipke, 2009). Limitations and peculiarities inherent in the use of the historical EVM Schedule Variance (SV) and Schedule Performance Index (SPI) caused (Lipke, 2009) to introduce Earned Schedule (ES) to resolve the issues (Naeni, 2010). 
"The EVM of an activity is a measure of the completed work and represents the budgeted cost of work performed, and indicates how efficiently the project team utilizes the project resources (Naeni, 2010)." There are several techniques to calculate EVM; one of the simplest techniques is Percent Complete (PC) (Naeni, 2010). The Percent Complete technique requires an individual in-charge to estimate how much of the activity is complete. The estimate is expressed in a percent, $35 \%$; however this technique only contributes to the uncertainty of the project. This approach is a highly subjective form of measuring a project's completion, which contradicts EVM's goal of being an objective method. An idea that has been presented is use linguistic terms during estimating procedures. For instance, instead using the project is about $50 \%$ complete the project manager would express linguistically that the project is half way completed. However, in order to use EVM functions these linguistic terms need to be translated into an integer. In 1965, Lotfi Zadeh, introduced fuzzy theory which explains uncertainty in systems or projects where uncertainty is caused by lack of clarity or fuzziness rather than randomness completely. Using fuzzy principles the linguistic terms for project completion are transformed into fuzzy number which can then be used in EVM functions (Naeni, 2010). As stated early there are other methods for determining EVM, but the simplest is using Percent Complete.

\subsection{Multi-project Environments}

\subsubsection{Issues with Critical Chain Method}

Applying the Critical Chain Method in an environment consisting of multiple ongoing projects does present some challenges to the management team. The first challenge that exists is when different projects require the same resource and require that resource concurrently (Tian, 2010). This causes the resource or operator to become scarce or causes the operator to multi-task. An additional challenge is when individual project managers place priority on their project and insist that a resource/ operator attend to their project ahead of all other projects. In effect causing the delays in other projects because the 
resource/ operator as ceased service on what was currently being worked on and moved on to the "priority" project. Another obstacle is the cascade effect: changes in cost, duration, and resources in the project causing changes to sub-projects (Tian, 2010). In order to meet these complexities that occur in multi-project environments, the scheduling and planning for these conditions are divided into the following steps (Tian, 2010):

1) Calculate the priority of each project.

2) Plan and schedule each project in accordance with CCM.

3) Identify the task in which resources are conflicting and schedule the projects to avoid such conflicts.

4) Set the project and feeding buffers.

5) Manage the buffer zone effectively

\subsection{Data Analysis}

\subsubsection{Paired $t$ Test}

The paired $t$ test is implemented when it is necessary to analyze the difference between the means of two groups and conditions are met: the sample populations are related and the groups are not independent from one another. The dependency of the groups happens because the objects or operators are paired based on a characteristic or repeated measurements were gathered. Regardless of the scenario the difference between the two observations, delta $\Delta$, is the variable of interest (Levine et al., 2001).

There two approaches for related-sample problems. The first approach matches objects or operators based on a similar characteristic. The other approach to the related-samples problem requires multiple measurements to be taken from the same object or operator. The assumptions that us made in order to apply this technique is that the same objects or operators will behave the same if they are treated the same. The emphasis of this analysis is to reveal any possible differences between two measurements of the same objects or operators caused by varied conditions (Levine et al., 2001). The paired $t$ test aims 
at studying the difference between two measurements through means of reducing the effect of variation caused by the objects or operators (Levine et al., 2001).

\subsection{2 $t$ Test for the Mean Difference}

In order to use the $t$ test for the mean difference a few assumptions are inferred: the population is normally distributed and the sample size is not very small (Levine et al., 2001).

$$
\begin{gathered}
\text { Reject } H_{O} \text { if } t>t_{n-1} \\
\text { or if } t<-t_{n-1} ; \\
\text { otherwise do not reject } H_{O} \\
\text { Reject } H_{O} \text { if } t_{\text {stat }} \text { is large } \\
\text { and if } P \text { is small; } \\
\text { otherwise do not reject } H_{O} \\
H_{O}: \mu_{D}=0\left(\text { where } \mu_{D}=\mu_{1}-\mu_{2}\right) \\
H_{1}: \mu_{D} \neq 0
\end{gathered}
$$

\subsubsection{One-Way Analysis of Variance (ANOVA)}

In order to determine if there are differences among the parameters of several groups (alternative materials, methods, or treatments) the analysis of variance or ANOVA technique is used (Levine et al., 2001). The ANOVA procedure is used to evaluate the means of different groups. The results of the ANOVA test produce categories labeled within group and among group. The "within group" variation is experimental error, while "among group" variation is attributed to treatment effects (Levine et al., 2001). . The analysis of variance method assumes that group(s) under evaluation has populations that randomly and independently gathered, normally distributed, and are of equal variance (Levine et al., 2001).

\subsubsection{The One-Way ANOVA F Test Statistic}

The F-test statistic follows the F distribution and the degrees of freedom are found using: $\mathrm{c}-1$, where $\mathrm{c}$ is the number of groups or levels. The null hypothesis would be rejected if the computed F test statistic exceeded the upper-tailed critical value $\mathrm{F}_{\mathrm{u}}$ from the $\mathrm{F}$ distribution ((Levine et al., 2001)). 


$$
\begin{gathered}
\text { Reject } H_{O} \text { if } F>F_{u} \\
\text { otherwise do not reject } H_{O} \\
\text { Reject } H_{O} \text { if } F \text { is large } \\
\text { and if } P \text { is small; } \\
\text { otherwise do not reject } H_{O} \\
H_{O}: \mu_{A}=\mu_{B}=\mu_{C}=\cdots \mu_{i}=0 \\
H_{A}: \text { Otherwise }
\end{gathered}
$$

Three assumptions are made while employing the F test statistic: 1) Randomness and

independence 2) Normality 3$)$ homogeneity of variance $\left(\sigma_{1}^{2}=\sigma_{2}^{2}=\ldots \ldots=\sigma_{c}^{2}\right)$. If the normality assumption is not met there are nonparametric alternatives that can be utilized (Levine et al., 2001).

\subsection{Conclusion}

The literary review revealed that little or no comparisons have been made between milestone projects versus non-milestone projects. The principles that govern critical chain project management are adapted and modified to meet the requirements for this experiment and are explained in later chapters. The concept of earned value management is applied to the design of the experiment providing an essential measurement for comparison between the project methodologies. Over the next several chapters the information provided in the literature review is applied to form the basis for the experiment and for the analysis of the data. 


\section{Chapter 3: Methodology}

\subsection{Introduction}

Eliyahu Goldratt (1997) concluded that the application of critical chain project management was a more effective method than critical path project management for managing a project. The literary review revealed additional evidence that supported Goldratt's conclusion; as well as a mathematical model showing the difference between critical path and critical chain project management methodologies. The objective was to develop and apply a method that compared these different project management methods in a university environment. The proposed methodology allowed for a statistical comparison of total time, quality, and quality of time spent on the project. These three criterions were the foundation of the methodology and are developed further in this chapter.

\subsection{Developing the Methodology}

The distinction Goldratt (1997) made between critical path and critical chain project management methodologies showed that CCPM managed projects were more effective and efficient. The estimation of contingency, human behavioral tendencies and existence of multi-tasking among operators were three of the factors that affected project scheduling and lead time.

The critical path project management structure incorporated project milestones that governed the implementation of a project and encouraged certain human behavioral tendencies that negatively affected a project. Goldratt (1997) better describes the adverse effects that occur when CPPM is implemented. The first negative effect is the existence of contingency in each activity which directly affects the lead time. The presence of the contingency allows for uncertainty to be mitigated, however a project containing an inordinate amount contingency has the same effect as uncertainty. Human behavioral tendencies, not 
reporting early finish times and student syndrome, adversely affect projects (Goldratt, 1997). Lastly, multi-tasking results in longer lead times for activities in a project resulting in extended project duration.

Theoretically critical chain project management significantly reduces the amount of contingency time incorporated into the project, by extracting the safety time in each activity and relocating half the original amount at the backend. The research also revealed CCPM negated the effect of human behavioral tendencies: student syndrome and Parkinson's Law. The goal of critical chain project management is to modify the way people interact and operate in a project environment.

The critical path project incorporates a sequence of milestones (milestone project), while the modified critical chain method eliminates the milestone deadlines resulting in a project with a beginning and end date (duration project). In order to compare the milestone method and the duration method three quantitative measurements were created and collected: total time, quality and quality of time.

\subsubsection{Total Time}

The total lead time of a project and the total time spent on a project are two different entities. The focus of this methodology was on the total time spent on the project; this variable was measured in hours. The total time of the project was used because theoretically the modified critical chain project results in a shorter lead time than critical path.

\subsubsection{Quality}

Addressing the quality of the project also allowed for a comparison analysis of critical path and critical chain project management methodologies. The quality aspect incorporated human behavioral tendencies and provided another source of measurement to perform a comparison. The quality of each project was determined by the final score. The score was calculated by testing the project to determine if it met the requirements. 


\subsubsection{Quality of Time}

Earned value management provided another variable of measurement that was used in the comparative analysis. The EVM tool introduced into this project combined the total time spent on a project and quality to create the statistic (Equation 1).

$$
\begin{gathered}
\frac{\text { Quality }}{\text { Total Time Spent on a Project }}=\frac{\text { Project Score }(\%)}{\text { Total Time }(\text { Hours })}=\frac{\%}{\text { Hrs. }} \\
\text { Equation 1: Quality of Time, EVM }
\end{gathered}
$$

This measurement was used to calculate quality of hours spent working on the projects. For instance two operators (students) may obtain a score of 90 points out of 100 but their total hours spent working on the project are different: 25 and 15 hours respectfully. The result of this EVM tool distinctly distinguishes the operators and shows that operator one works less efficiently then the second operator. This tool was applied to the data produced to determine if there was significant difference between milestone and duration.

\subsection{Experiment Design}

The experiment allowed for a comparison between CPPM (Milestone) and CCPM (Duration) in a physical environment and outside the realm of paper theory. The two project models were designed for and implemented in a university environment. Both of the project methodologies contained identical performance requirements (critical steps) which allowed for the statistical comparison. The critical steps did not require the students involved in the experiment to learn a new technique or skill from one model to the next model. The students implemented each project management model which produced data for the quantitative measurements: total time, quality and quality of time. The entire class performed the milestone model concurrently and then performed the duration model.

An important aspect addressed in the research is the presence of multi-tasking among operators. Multi-tasking among operators in a company is a common occurrence and has an adverse effect in a 
project environment. Critical chain project management attempts to eliminate this effect through improved project scheduling. In the university setting the operators, the students, experience the effect of multitasking though means of their classes. Full-time and part-time students are distinguished by the amount of units they are enrolled in while attending the university. The students involved in the experiment are full-time students resembling full-time employees or operators. The units for each student are compared to the quantitative measurements to determine if multi-tasking has an effect on project lead time and quality.

The main difference between critical path and critical chain project management methodologies the lead time of the project. The research has revealed CCPM theoretically shortens lead time. In the case of this research the lead time for both projects were assigned a start and end date by the professor. To account for these predetermined dates an adjusted approach was developed in order to apply CPPM and CCPM theories. The two projects, milestone and duration, and their comprised components are explained in this section, while the statistical comparison is explained in the section titled "Statistical Model".

\subsubsection{Milestone Project Management Model}

The milestone project management (MPM) model was comprised of milestones throughout the entirety of the project. These milestones represented the critical steps of the project that were required for the project to be completed and function according to the specifications. The selected the due dates for each milestone were determined by the magnitude of each step. The magnitude of each step was determined by the amount of points assigned to the step divided by the overall point total of the project, which resulted in a percentage. The percentage was applied to the overall length of the project to provide the length of each milestone. The amount of the contingency time given to each step was simply taking the value produced from the previous step and rounding up to the next whole number. These steps resulted in the milestone model for the experiment. 


\subsubsection{Duration Project Management Model}

Unlike the MPM model the duration project management (DPM) model eliminated the milestones and became a project with start and end date. The duration model removed the required milestone completion dates and the contingency within each milestone. The DPM model helped mitigate human behavioral patterns by allowing the operator to begin next step at the conclusion of previous. This allowed for immediate commencement of the next step and eliminated the idle time (Parkinson's Law) commonly found milestone projects.

\subsection{Statistical Model}

In order to compare the two project management methodologies a statistical model was applied: the paired $t$ test. The paired $t$ test allowed for a direct comparison of the three test measurements of two methodologies. The paired $t$ test compares the sample means from the two populations, in this case the milestone and duration projects, in order to determine if there is a significant difference. In order to apply the paired $t$ test three assumptions were made about the populations: normally distributed and not relatively small. The Anderson-Darling Test for Normality determined if the data was normal. If the data was normal the paired $t$ test was used to compare MPM and DPM; if the data was not normal a nonparametric test, One-Sample Wilcoxon test was applied to the data. The second statistical method used in this research was the ANOVA test to determine if the selected independent factors affect the dependent variable. 


\section{Chapter 4: Design}

\subsection{Introduction}

The developed methodology in chapter three is applied in the design of the experiment. All of the requirements, specifications and conditions are discussed in this chapter, along with the design and implementation of the two project management theories that have been developed in this research.

\subsection{Hypothesis}

The research thus far has lent itself to the conclusion that implementing critical chain project management is a more efficient and effective method for managing projects. The null hypothesis, $\mathrm{H}_{\mathrm{O}}$, states that there is no difference between the two population means, while alternative, $\mathrm{H}_{1}$, states there is a difference. The difference in the populations means-MPM and DPM-is represented by the $\mu_{\mathrm{D}}$ in the hypothesis. Below is the hypothesis for all three quantitative measurements - total time, quality and quality of time-collected in this research.

\subsubsection{Total Time}

The null hypothesis for the total time states: there is not a difference in the university environment between MPM and DPM.

$$
\begin{gathered}
H_{O}: \mu_{D}=0 \\
H_{1}: \mu_{D} \neq 0 \\
\text { Reject } H_{O} \text { if } t_{\text {stat }} \text { is large } \\
\text { and if } P \text { is small; } \\
\text { otherwise do not reject } H_{O}
\end{gathered}
$$

\subsubsection{Quality}

The null hypothesis for the quality states: there is not a difference in the university environment between MPM and DPM.

$$
\begin{array}{r}
H_{O}: \mu_{D}=0 \\
H_{1}: \mu_{D} \neq 0
\end{array}
$$




$$
\begin{gathered}
\text { Reject } H_{O} \text { if } t_{\text {stat }} \text { is large } \\
\text { and if } P \text { is small; } \\
\text { otherwise do not reject } H_{O}
\end{gathered}
$$

\subsubsection{Quality of Time}

The null hypothesis for the quality of time states: there is not a difference in the university environment between MPM and DPM.

$$
\begin{gathered}
H_{O}: \mu_{D}=0 \\
H_{1}: \mu_{D} \neq 0 \\
\text { Reject } H_{O} \text { if } t_{\text {stat }} \text { is large } \\
\text { and if } P \text { is small; } \\
\text { otherwise do not reject } H_{O}
\end{gathered}
$$

\subsection{University Environment}

The experiment for this research was performed in a university environment at the California Polytechnic State University, San Luis Obispo (Cal Poly SLO). The students involved in this experiment are in the Industrial and Manufacturing Engineering Department (IME). The academic quarters at Cal Poly SLO are eleven weeks in total: ten weeks instruction and one week for finals.

\subsubsection{Course Selection}

The Industrial \& Manufacturing Engineering Data Management and System Design (IME 312) course was selected for the experiment. The IME 312 course was chosen because it required the students to complete multiple individual projects throughout the academic quarter. In addition each project required the student to design, build and test to meet certain design and functional specifications. The occurrence of multiple projects lends itself to the use of the paired $t$ test, for the repeated measurements of: total time, quality and quality of time.

\subsubsection{Assumptions}

There were several assumptions that were made in order to conduct this experiment. These assumptions consisted of the following: 
- All the students involved were enrolled in a least the minimum number of units to be considered a full-time student by the university

- The techniques and skills required to complete each project were ascertained at the beginning of the academic quarter

- No new techniques or skills were required to from the first project to the second project

\subsection{Project Management Models}

In order to accurately compare the three measurements - total time, quality and quality of timefor MPM and DPM two models were developed: critical path and critical chain. Each model was uniquely planned to resemble the project management methodology it would represent in the experiment.

However, the uniqueness of the models only existed in the structure of their scheduling; the activities that comprised the models were the identical in nature.

The professor instructing the class provided each project's begin and end dates, assigned the total points possible for each activity in the project and designed the theme for each project. Although the theme of each project was different techniques and skill required to complete each project were the same: no new material or development of a new skill was needed between projects.

For both projects the students were given an explanation of the project guidelines and requirements. The students were instructed to record the total time spent on the project-design, development and testing — on the provided worksheets (Figure $4 \&$ Figure 5). These worksheets are snapshots of the entire worksheets located in Appendix A, Figure 23: Figure 24. 


\begin{tabular}{|c|c|c|c|c|c|c|c|c|c|c|}
\hline $\begin{array}{l}\text { Activity/ } \\
\text { Milestone } \\
\text { Name }\end{array}$ & \multicolumn{2}{|c|}{ Simulated Clock } & \multicolumn{2}{|c|}{ Dues Collection } & \multicolumn{2}{|c|}{ Deposit } & \multicolumn{2}{|c|}{ Bills Payment } & \multicolumn{2}{|c|}{$\begin{array}{c}\text { Monthly Report \& } \\
\text { Additional } \\
\text { Features }\end{array}$} \\
\hline $\begin{array}{l}\text { Milestone } \\
\text { Number }\end{array}$ & \multicolumn{2}{|c|}{1} & \multicolumn{2}{|c|}{2} & \multicolumn{2}{|c|}{3} & \multicolumn{2}{|c|}{4} & \multicolumn{2}{|c|}{5} \\
\hline \multirow[t]{4}{*}{$\begin{array}{c}\text { Date Due I } \\
\text { Time }\end{array}$} & $2 / 15 / 11$ & 11:59am & $2 / 22 / 11$ & $11: 59 \mathrm{pm}$ & $2 / 24 / 11$ & $11: 59 \mathrm{pm}$ & $2 / 26 / 11$ & $11: 59 \mathrm{pm}$ & $2 / 29 / 11$ & $11: 59 \mathrm{pm}$ \\
\hline & Date & $\begin{array}{c}\text { Hours } \\
\text { Worked }\end{array}$ & Date & $\begin{array}{l}\text { Hours } \\
\text { Worked }\end{array}$ & Date & $\begin{array}{c}\text { Hours } \\
\text { Worked }\end{array}$ & Date & $\begin{array}{c}\text { Hours } \\
\text { Worked }\end{array}$ & Date & $\begin{array}{c}\text { Hours } \\
\text { Worked }\end{array}$ \\
\hline & $2 / 14$ & $30 \mathrm{~min}$ & $2 / 16$ & 4 hours & & & & & & \\
\hline & $2 / 15$ & $10 \mathrm{~min}$ & $2 / 21$ & 2 hours & & & & & & \\
\hline
\end{tabular}

Figure 4: MPM Methodology Worksheet (Milestone)

The times collected through the milestone worksheet required the students to record the times under the respective activity. The students were sent two alerts via email one day and twelve hours before the activity was scheduled for completion. These times were collected from the students on the scheduled completion date for each activity.

\begin{tabular}{|l|l|l|l|}
\hline Date & Hours Worked & Date & Hours Worked \\
\hline $2 / 4$ & 30 min & & \\
\hline $2 / 4$ & 4 hours & & \\
\hline $2 / 5$ & 3 hours & & \\
\hline $2 / 6$ & 45 min & & \\
\hline $2 / 8$ & 2 hours & & \\
\hline $2 / 9$ & 10 min & & \\
\hline
\end{tabular}

Figure 5: DPM Methodology Worksheet (Duration)

The collection of times through the duration worksheet had the students record their times each time they worked on the project. Similar to the milestone project, students received alerts as the duration project progressed. The alerts were sent at the four points throughout the project: $25 \%, 50 \%, 75 \%$ and a day before the scheduled completion date. The project was scheduled for 16 days, thus the $25 \%$ alert would be sent on the fourth day and the following alerts would be sent on their corresponding day.

The milestone and duration models had identical activity skills. As stated earlier, no new skills or techniques were taught or introduced to the students between the projects. The ability to develop tables, 
forms, queries and reports were the only required skills to complete the projects. The tools and methods that were necessary to complete the four requirements listed above were taught and practiced the first several weeks of the academic quarter.

The original length of the milestone project was scheduled for thirteen days, however after length for each activity was the project's completion date was moved to a later date. The "minimum required days" was based off the original thirteen day length because and did not include contingency in individual activities, which is the basis for critical path project management. The calculations for each activity in the milestone model followed the following procedure and the data is shown in Table 1.

1. Calculate the importance of each activity based the on the percentage: "Points Percentage" column.

2. Multiple the previous value and the "length of project" value to determine the minimum required days

3. Round the values in the "minimum required days" to the next whole day

\begin{tabular}{|c|c|c|c|c|}
\hline $\begin{array}{c}\text { Total } \\
\text { Points }\end{array}$ & 300 & \multicolumn{3}{|l}{} \\
\cline { 1 - 2 } $\begin{array}{c}\text { Length of } \\
\text { Project }\end{array}$ & 13 & \multicolumn{3}{|l}{} \\
\cline { 1 - 2 } Activity & $\begin{array}{c}\text { Points } \\
\text { Possible }\end{array}$ & $\begin{array}{c}\text { Points } \\
\text { Percentage }\end{array}$ & $\begin{array}{c}\text { Minimum } \\
\text { Required Days }\end{array}$ & Contingency \\
\hline 1 & 10 & 0.033 & 0.433 & 1 \\
\hline 2 & 150 & 0.500 & 6.500 & 7 \\
\hline 3 & 40 & 0.133 & 1.733 & 2 \\
\hline 4 & 40 & 0.133 & 1.733 & 3 \\
\hline 5 & 60 & 0.200 & 2.600 & 2 \\
\hline & & & & \\
\hline
\end{tabular}

The values in the "contingency" column are the required lengths for their respective activity. The duration project was the first model that was implemented by the students followed by the milestone 
model. There were no calculations for the activity lengths in the duration model because the model represented the critical chain structure.

\subsubsection{Milestone Project Management Model}

The overall length for this model was sixteen days and the objective for the milestone project required the students to design and develop a database control system for a homeowners association. The intended user for the database homeowners association is the treasurer of the homeowners association. The five milestones assessed for the quality of the project were:

- Simulated Calendar

- Dues Collection

- Deposit

- Bills Payment

- Monthly Report and Additional Features

The students were verbally informed of the expectations, both desired and undesired, for each category; they were also given a link to a web page with the project description and expectations. Figure 6 below, shows was the map provided for the students for the critical path project. 


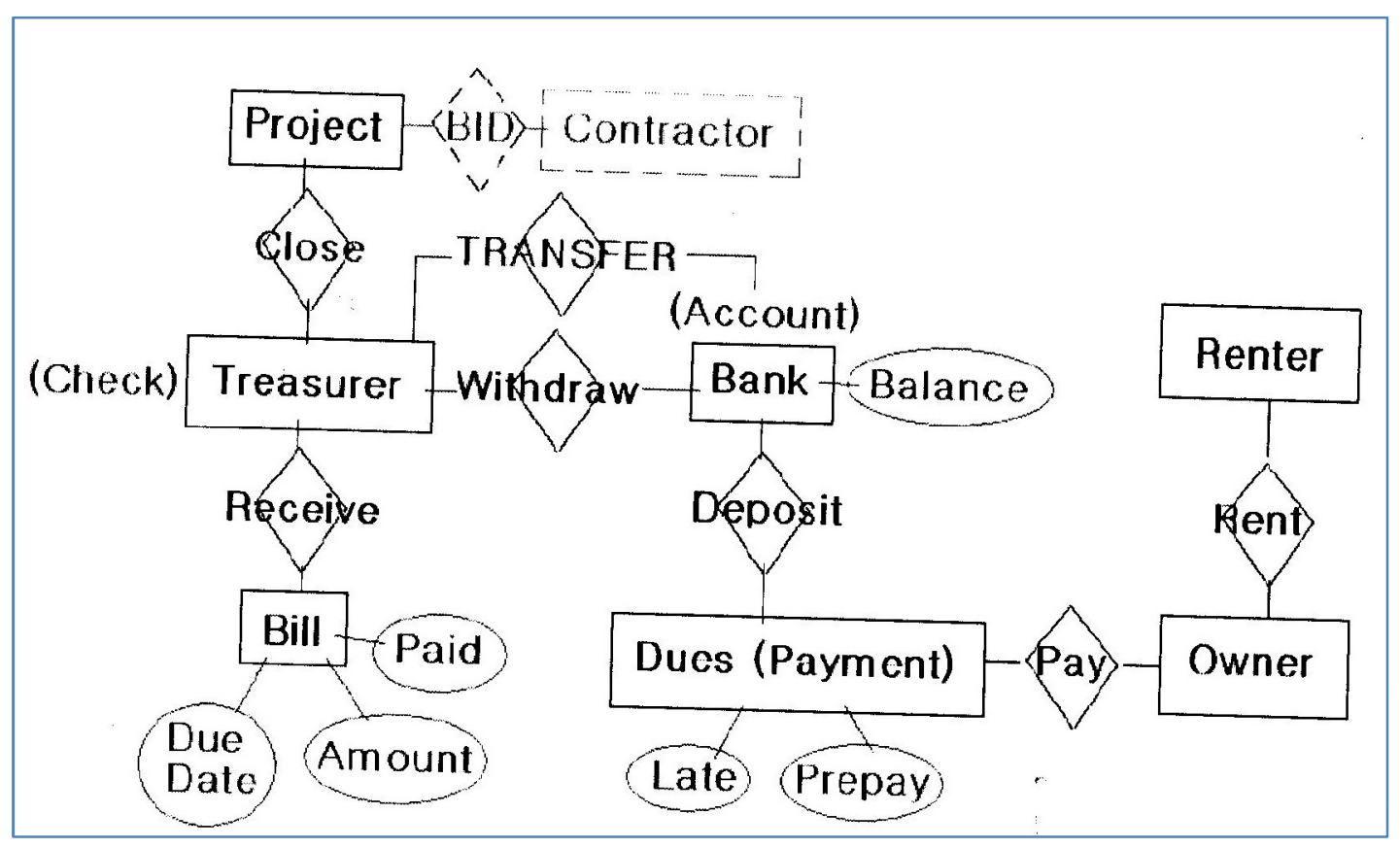

Figure 6: MPM Project Map (Milestone)

The objective of the simulated calendar allowed the database to simulate future of dates. The operators (students) were instructed not to include time values in the simulation: hours, minutes, and seconds (HH:MM:SS). The requirements for the Dues Collection milestone consisted of four functions: normal payment, prepay, late payment, and delinquency report. In the cases of the late payment and delinquency report functions, students were required to add an additional fee (late payment) and locate all history of payments (delinquency report).

The Deposit activity's required feature allowed for money to be deposited into the system: checking or savings deposit and purchase of a CD. The Bills Payment function allowed money to be taken from the system and produce all the reports associated with the withdrawal. The requirements for the Monthly Report and Additional Features are the ability to produce monthly financial activities within the homeowners association and allow complete navigation through the database system. 


\subsubsection{Duration Project Management Model}

The overall the length for the duration project was sixteen days. The objective for the duration project required the students to design and develop a database control system for a library. The intended users for the database control system are the Library Director, Circulation Front Desk Checkout Clerk, Return Collection Clerk, Inventory Auditing Personnel, and Students \& Faculty. The five activities for assessed for the quality of the project consisted of:

- Simulated Calendar

- $\quad$ Student \& Faculty Page

- Circulation Desk \& Return Area

- Inventory Auditing page

- Director page

The students were verbally informed of the expectations, both desired and undesired, for each category; they were also given a link to a web page with the project description and expectations. The map below (Figure 7) was given to the students to assist in the development of the project.

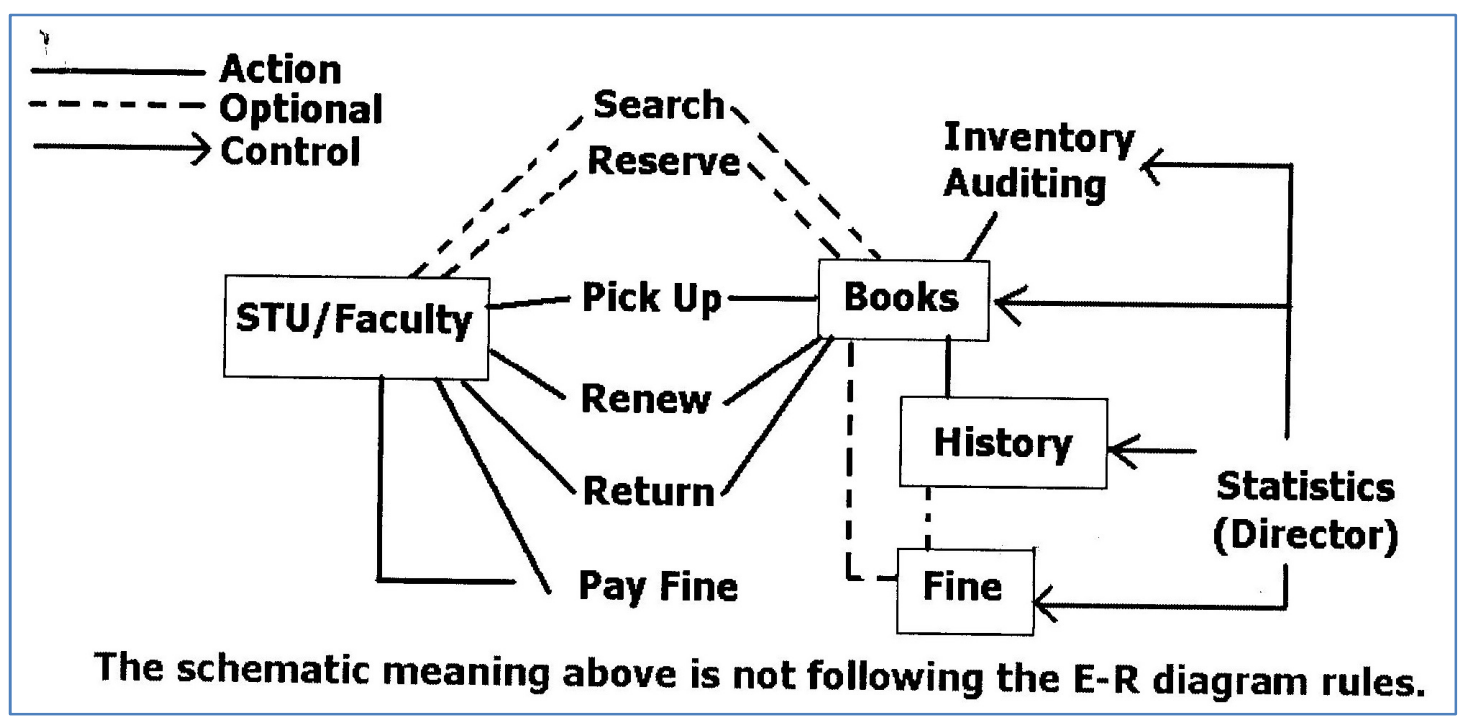

Figure 7: DPM Project Map (Duration) 
The expectations for the first milestone category, Simulated Calendar, required the students to create a calendar system that was capable of simulating future calendar dates. The students were instructed not to include time values in the simulation: hours, minutes, and seconds (HH:MM:SS). The purpose of creating the simulated calendar feature allowed for future simulation of dates.

The functions required for the Student \& Faculty page were: allow both students and faculty to search for books and book status, reserve books that are not currently checked out or reserved, renew or extend the check out of a book, recall/ request a book that is currently checked out and allow for the account manager to check the status of all books. The requirements for the Circulation Desk \& Return area mandated that students create a system capable of allowing books to be borrowed for a certain time period and then returned, alerts for the library if books were over due, changing the status of the book from available to unavailable and back again, and prevent students from borrowing books if the books if the book was marked as reserved.

The requirements and expectations for the Inventory Auditing page are such that: if a search is conducted for a certain book and resulting status of that book is lost or missing, library management is then able to trace the history of the book to determine that last person who checked out the book. The expectations for the final assessment category, the Director page, required the students to develop an area that summarized the statistics of the inventory for the entire library: number of times a book as been checked out, which people have checked out a certain book, how many books a student currently has checked out, check out history of an individual student and etc. The purpose for this page was to allow management to manage library operations. 


\subsection{Statistical Approach}

MINITAB, a statistical analysis software program, was used to perform the data analysis. In order to test the hypotheses paired $t$ tests were applied to each set of data. Before the paired $t$ test was applied the Anderson-Darling Test for Normality was used to determine if each $\mu_{\mathrm{D}}$ data for each of the three measurements was normal. If the test revealed that the data was normal, the p-value $>0.05$, then the paired $t$ test method was implemented; if the test showed that the data was not normal then the nonparametric tool, the One-Sample Wilcoxon method, was used to determine if the there was a significant difference. The difference between the MPM and DPM, $\mu_{\mathrm{D}}$, for each student and total time, quality and quality of time was tested for normality because the two statistical analysis tools used in this research analyze the difference.

ANOVA tools were used to determine if the amount of units affected each of the three measurements: total time, quality and quality of time. The General Linear Model in MINITAB was used because the data was unbalanced, hence the Two-Way ANOVA cannot be used. The two independent factors (model) in the ANOVA test were unit and project method type, MPM and DPM, and the independent variable (response) was one of the three measurements. The p-value that is produced for each dependent factor reveals whether or not the factor is significant in the model. If the p-value $<0.05$, then the factor is significant and has an effect on the independent variable (response). 


\section{Paired T-Test and Cl: Milestone Score, Duration Score \\ Paired T for Milestone Score - Duration Score

Figure 8: Example MINITAB Paired t test

The statistics in Figure 8 were produced from the paired $t$ test function found in MINITAB. The p-value, seen below in the bolded box, results in the following statement: Reject $\mathrm{H}_{\mathrm{O}}$ because the p-value is $.009<\alpha=.05$, thus there is a significant difference between the two sample populations.

\subsection{Conclusion}

The design for both MPM and DPM methodologies were implemented by the students enrolled in the Industrial and Manufacturing Engineering 312 course. The hypothesis for this research is that there is no difference between the two project methodologies for the selected measurements. The quantitative results for this research are analyzed and discussed in the following chapter. 


\section{Chapter 5: Results and Analysis}

\subsection{Introduction}

This research aimed at determining if there was a significant difference in the total hours, quality and quality of hours between the milestone and duration project management methodologies. The application of the design resulted in the following results, in which further analysis of the data was completed.

\subsection{Results for the Project Management Models}

The research has shown that implementing critical chain project management results in a reduction of work time for operators because CCPM alters the way operators interact with the project. The change in work time between the two populations-MPM and DPM-is represented by the $\mu_{\mathrm{D}}$ in the hypothesis. The null hypothesis, $\mathrm{H}_{\mathrm{O}}$, states that there is no difference between the two population means, while alternative, $\mathrm{H}_{1}$, states there is a difference.

The decision rule is shown below:

$$
\begin{gathered}
H_{O}: \mu_{D}=0\left(\text { where } \mu_{D}=\mu_{1}-\mu_{2}\right) \\
H_{1}: \mu_{D} \neq 0
\end{gathered}
$$

$$
\begin{gathered}
\text { Reject } H_{O} \text { if } t_{\text {stat }} \text { is large } \\
\text { and if } P \text { is small; } \\
\text { otherwise do not reject } H_{O}
\end{gathered}
$$

The resultant data produced by the students is located in (Appendix B, Table 3: Table 4).

\subsubsection{Total Time}

The probability plot (Figure 10) for the difference of total time, $\mu_{\mathrm{D}}$, shows a p-value of 0.070 indicating the data is normal. The paired $t$ test function found located in MINITAB was applied in order to determine if there was a significant difference in total hours. The t-value is -1.05 and the p-value is $0.309>0.05$, therefore we fail to reject the null hypothesis hence there is no significant difference in the total hours between the methodologies (Figure 9). 


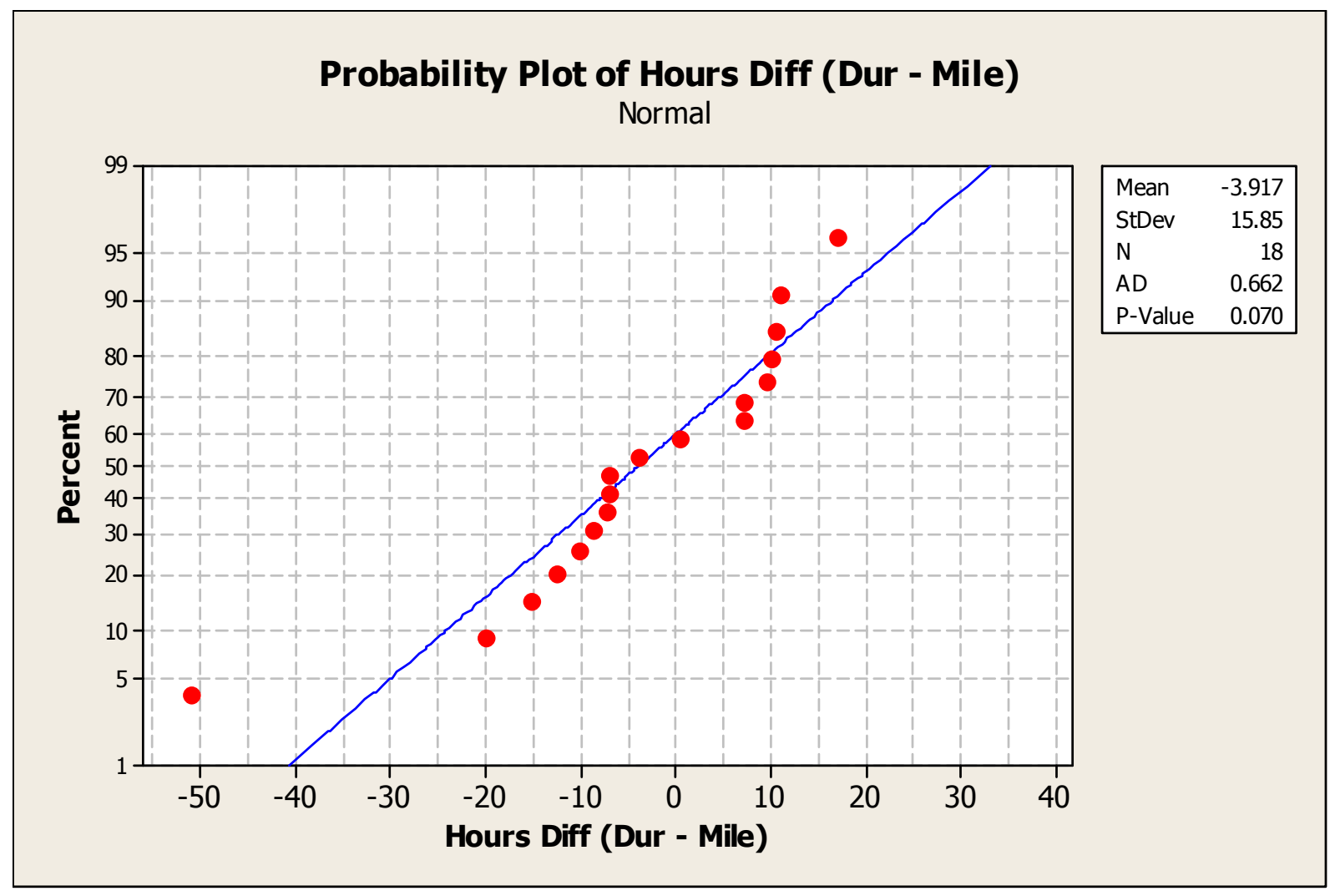

Figure 10: Probability Plot of Hours Difference

\section{Paired T-Test and Cl: Duration Hours, Milestone Hours}

Paired $\mathrm{T}$ for Duration Hours - Milestone Hours

$\begin{array}{lrrrr} & \text { N } & \text { Mean } & \text { StDev } & \text { SE Mean } \\ \text { Duration Hours } & 18 & 25.11 & 11.30 & 2.66 \\ \text { Milestone Hours } & 18 & 29.03 & 12.71 & 3.00 \\ \text { Difference } & 18 & -3.92 & 15.85 & 3.74\end{array}$

95\% CI for mean difference: $(-11.80,3.97)$

$\mathrm{T}$-Test of mean difference $=0$ (vs not $=0): \mathrm{T}$-Value $=-1.05 \quad$ P-Value $=0.309$

Figure 9: MINITAB Paired t Test for Hours 


\subsubsection{Quality}

The quality analysis was important aspect for this research because of its ability to reveal if one methodology produced a better quality project. The Anderson-Darling Test for Normality affirmed that the data associated with project quality was normal: p-value was 0.550 (Figure 11$)$. Therefore, the application of the paired $t$ test was used to determine if there was a significant difference.

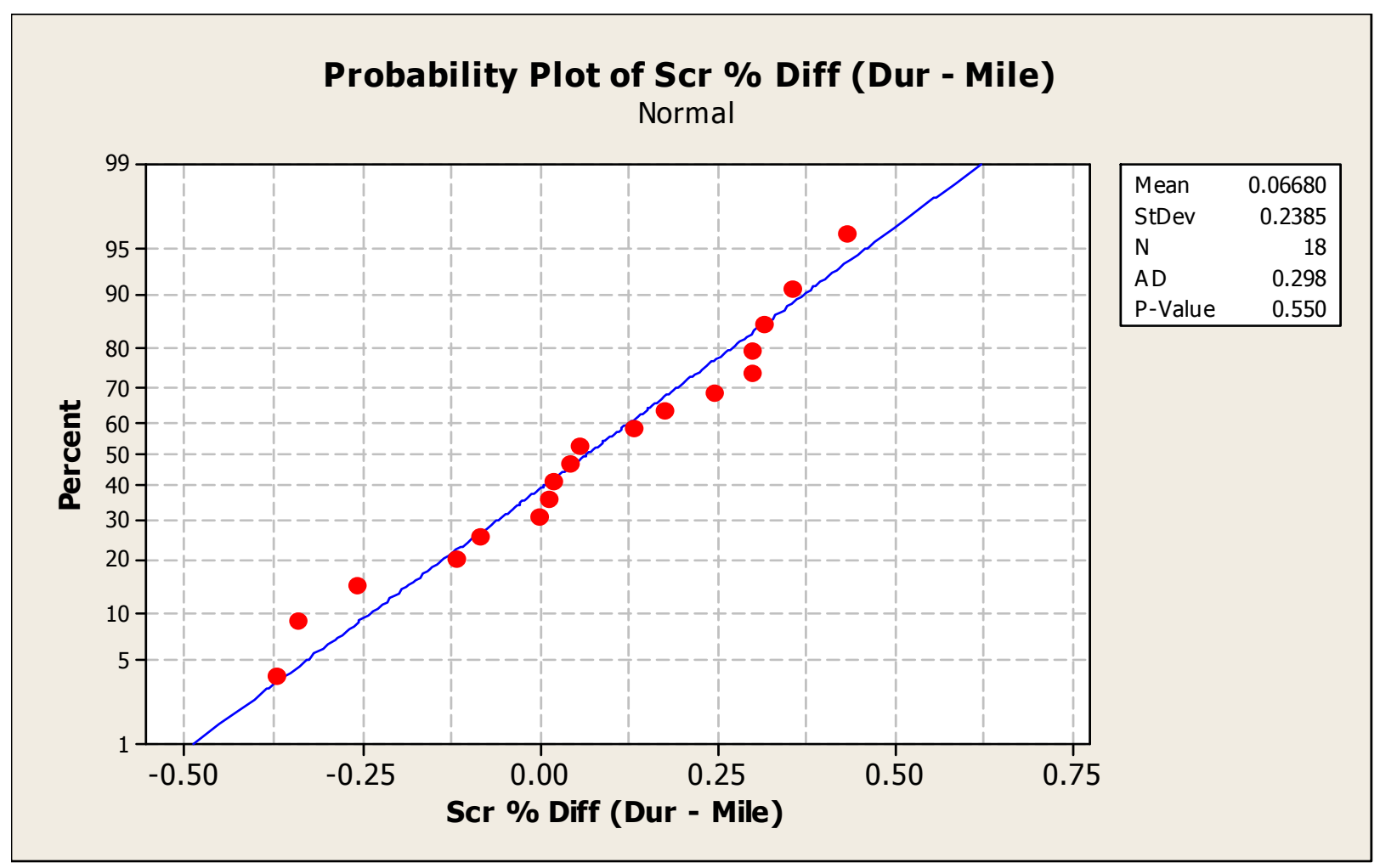

Figure 11: Probability Plot of Score (\%) Difference

The paired $t$ test function in MINITAB was applied to the final scores for each project. The original test produced findings showing a significant difference between MPM and DPM (Figure 12). The $\mathrm{t}$-value is -2.95 and the $\mathrm{p}$-value is $0.009<0.05$, thus the null hypothesis is rejected and there is a significant difference in the quality. 


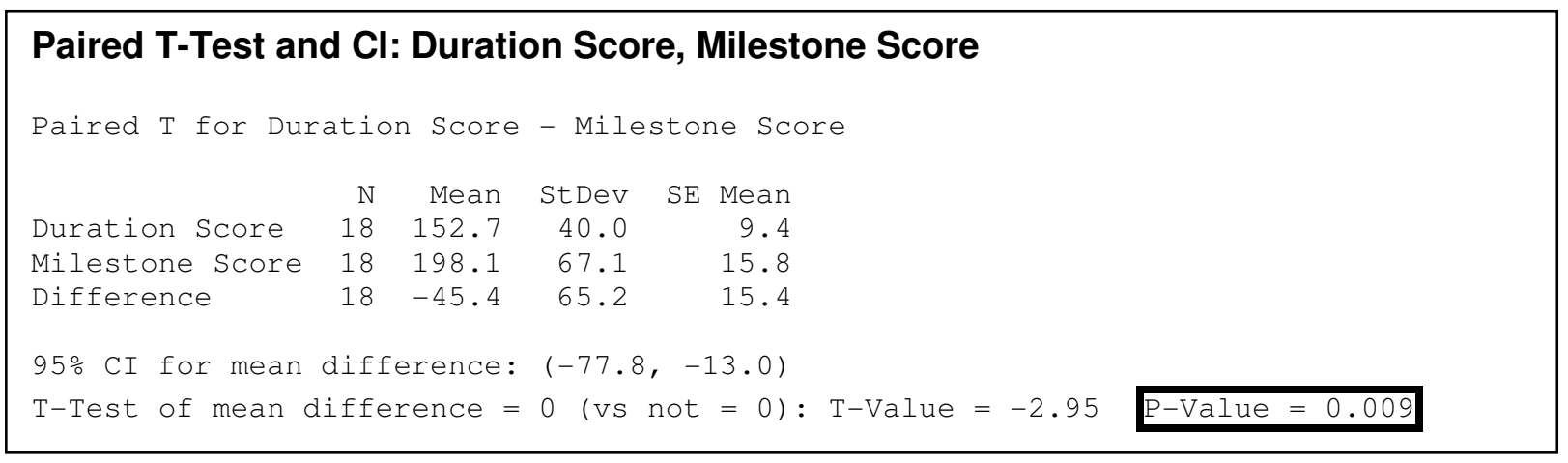

Figure 12: MINITAB Paired t Test for Score (points)

However, the two projects did not have equal points total, the duration project was out of 210 points, while the milestone project was out of 300 points. Therefore the scores for the models cannot be compared because their score total was not equal. In order to apply the paired $t$ test the scores for each project were converted into percentages.

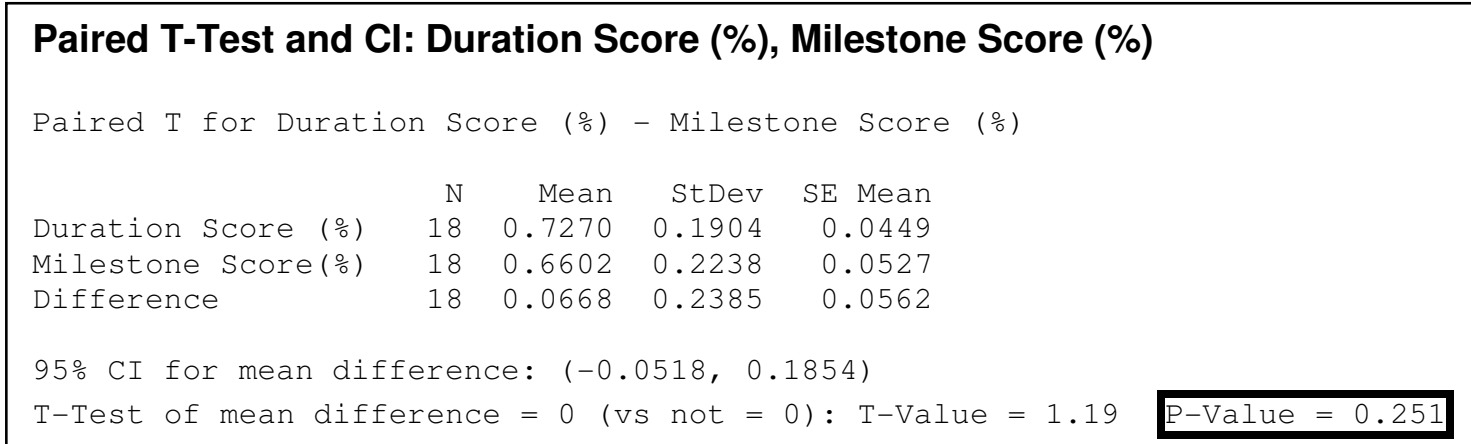

Figure 13: MINITAB Paired t Test for Score (Percentage)

Figure 13 shows the results for the application of the paired $t$ test for the percentages. The $\mathrm{t}$ value is 1.19 and the $\mathrm{p}$-value is $0.251>0.05$, therefore we fail to reject the null hypothesis thus there is no significant difference in the quality. 


\subsubsection{Quality of Time}

The previous two hypothesis tests for total time and quality resulted in similar conclusions, both failed to reject $\mathrm{H}_{\mathrm{O}}$; there was no significant difference between MPM and DPM. The quality of time measurement combines total time and quality to form the measurement quality per hour $(\% / \mathrm{hr})$. The Anderson-Darling Test for Normality (Figure 14) revealed that the sample data for quality of time was not normal; therefore the paired $t$ test cannot be applied.

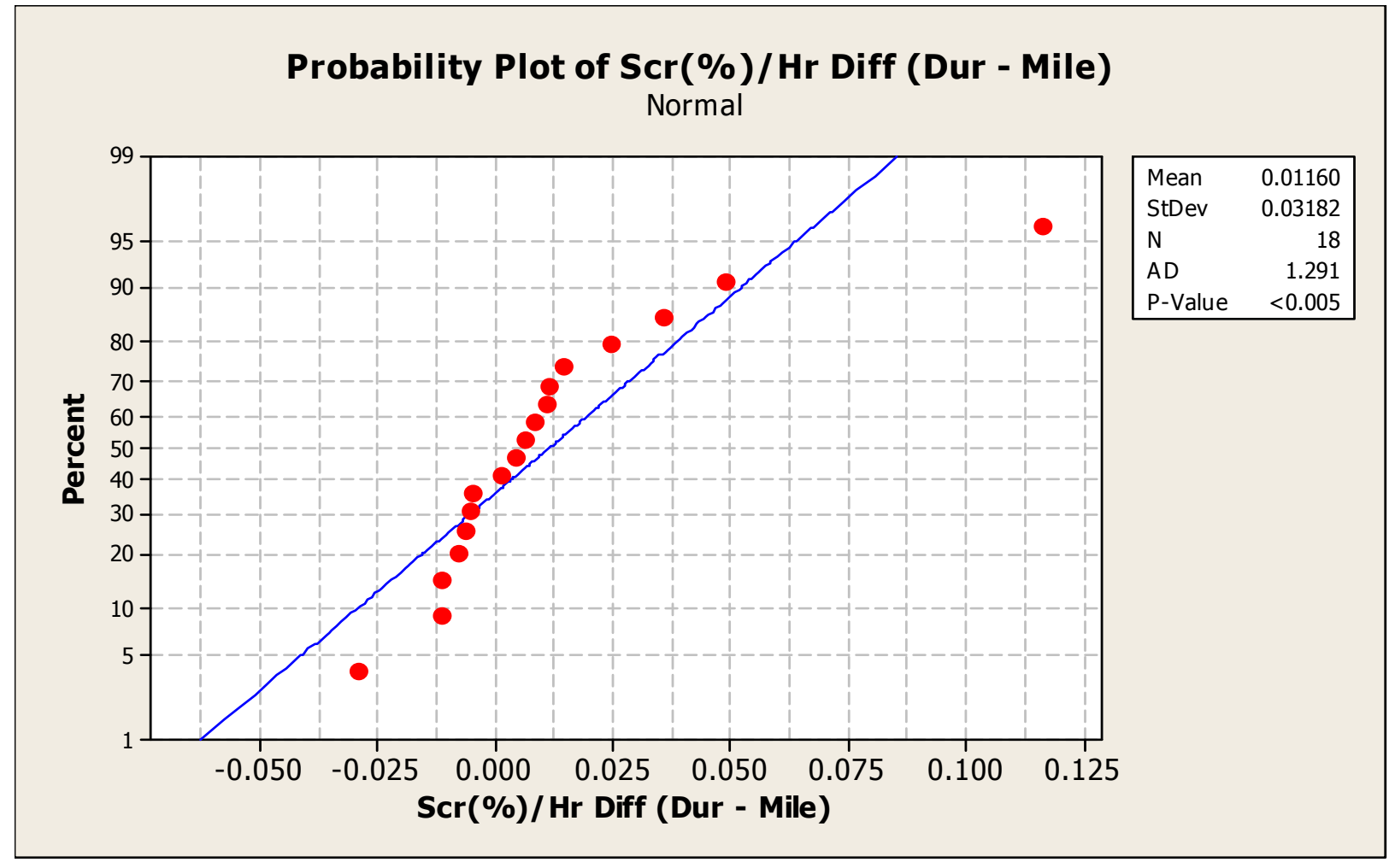

Figure 14: Probability Plot of Score (\%)/ Hr Difference

In order to determine if the there is a significant difference for the quality of time, which was not normal, a nonparametric test was needed: One-sample Wilcoxon Test. The hypothesis for One-Sample Wilcoxon test is the following:

$H_{O}: M_{1}=M_{2}$ (the median deviations from the target are equal) $H_{1}: M_{1} \neq M_{2}$ (the median deviations from the target are different)

$$
\begin{gathered}
\text { Reject } H_{O} \text { if } t_{\text {stat }} \text { is large } \\
\text { and if } P \text { is small; } \\
\text { otherwise do not reject } H_{O}
\end{gathered}
$$


The $t$-value is 116.0 and the p-value is $0.191>0.05$, therefore we fail to reject the null hypothesis thus there is no significant difference in the quality of time between the MPM and DPM (Figure 15).

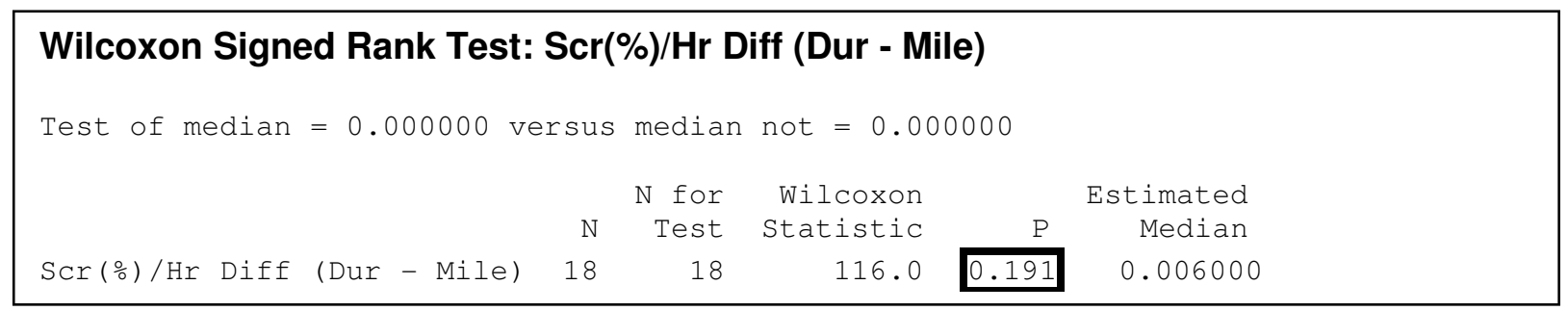

Figure 15: Wilcoxon Signed Rank Test Score (\%)/ Hr Difference

\subsubsection{Outlier Analysis}

Previous analysis of the probability plots revealed an outlier. The outlier was three standard deviations above the mean and was in 96.19 percentile. The value of the outlier was 0.116291 , while the three standard deviation value was 0.10706 . This outlier was excluded and the Anderson-Darling Test for Normality was repeated. The results for each measurement are shown in the figures below (Figure 16: Figure 18). The p-value for total time and quality increased; hence the normality for each data set increased and the paired $t$ test was repeated for each set of data. The normality test for quality of time showed the data to be normal, thus the paired $t$ test was applied.

\begin{tabular}{|l|c|c|}
\hline & \multicolumn{2}{|c|}{ Anderson-Darling Test for Normality } \\
\hline Measurement & P-Value with Outlier & P-Value without Outlier \\
\hline Total Time & 0.070 & 0.169 \\
\hline Quality & 0.550 & 0.659 \\
\hline Quality of Time & $<0.005$ & 0.365 \\
\hline \multicolumn{2}{|c|}{ Table 2: Anderson-Darling Test for Normality, P-Value changes }
\end{tabular}




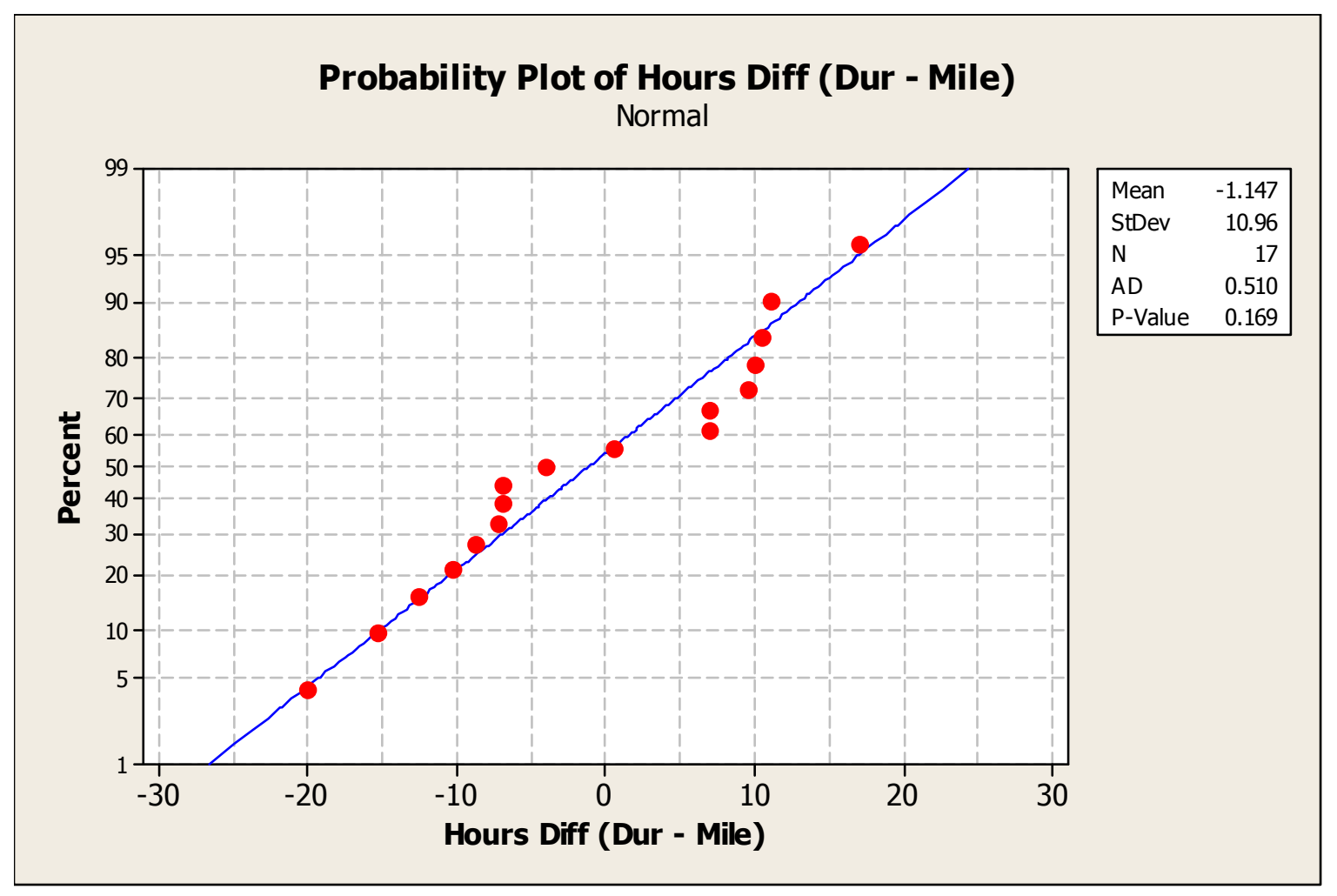

Figure 16: Probability Plot of Hours Difference (w/o Outlier)

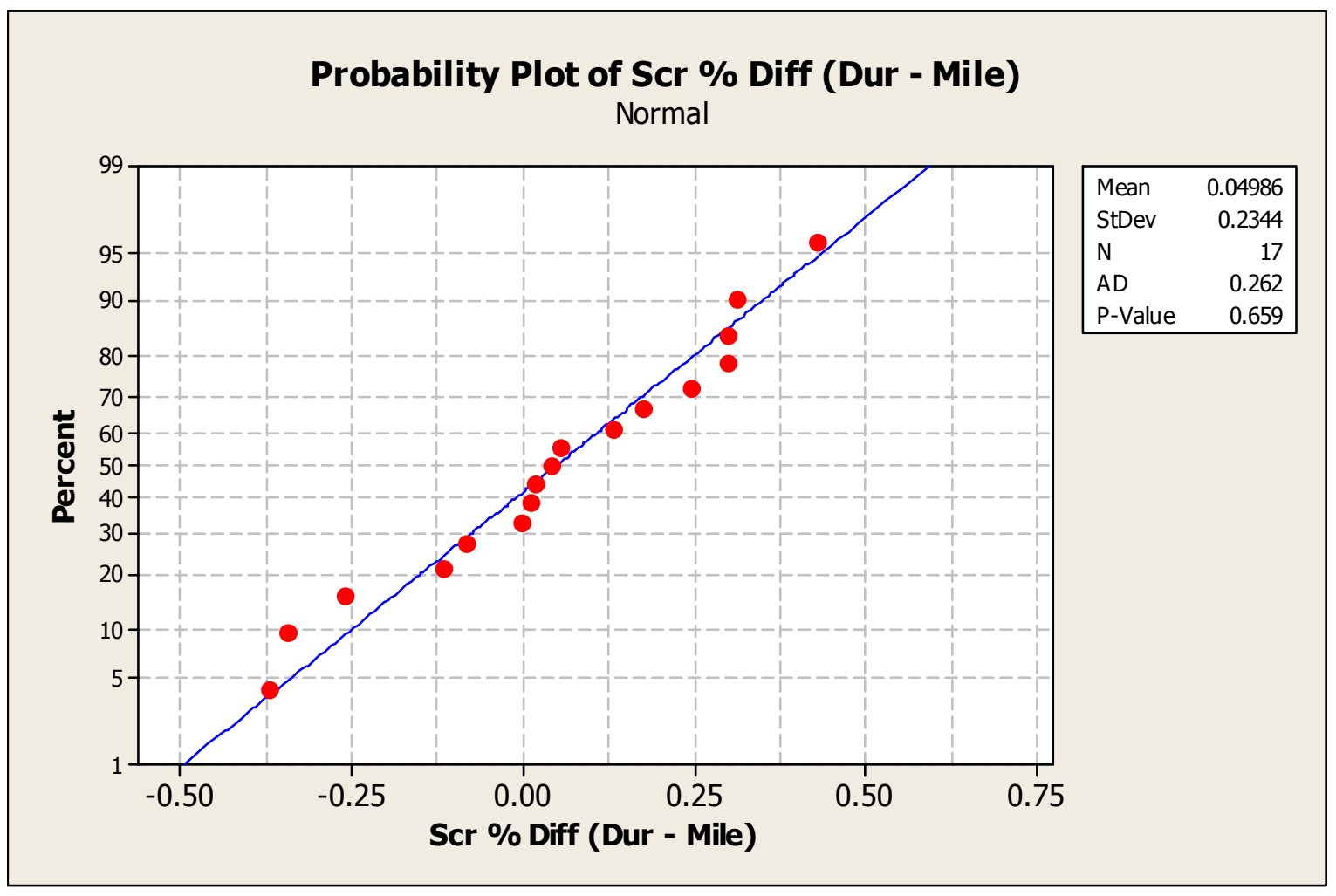

Figure 17: Probability Plot of Score (\%) Difference (w/o Outlier) 


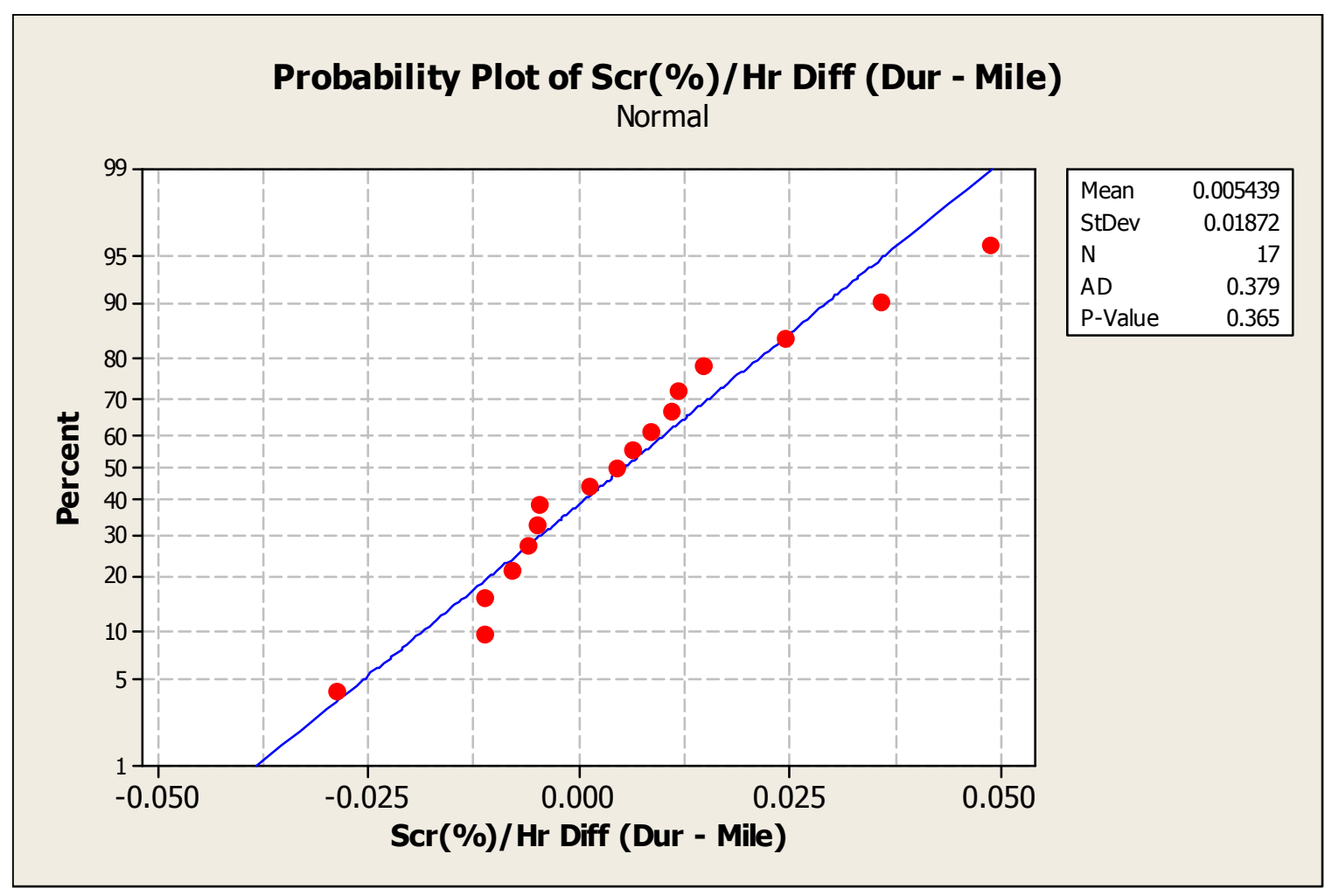

Figure 18: Probability Plot of Score (\%)/ Hr Difference (w/o Outlier)

The application of the paired $t$ test resulted in the following t-values and p-values for the total time, quality and quality of time (Figure 19). We fail to reject the null hypothesis because the p-values were $0.672,0.393$ and $0.248>0.05$, thus there is no significant difference in the total time, quality and quality of time between the MPM and DPM.

\section{Paired T-Test and Cl: Duration Hours, Milestone Hours}

$\mathrm{T}$-Value $=-0.43 \quad$ P-Value $=0.672$

Paired T-Test and Cl: Duration Score (\%), Milestone Score (\%)

$\mathrm{T}$-Value $=0.88 \quad$ P-Value $=0.393$

Paired T-Test and Cl: Duration (Scr(\%)/Hr), Milestone (Scr(\%)/Hr)

$\mathrm{T}$-Value $=1.20 \quad$ P-Value $=0.248$

Figure 19: T and P Values for Hours, Score and Score/ Hrs (w/o Outlier) 


\subsubsection{Multi-Tasking Analysis}

The General Linear ANOVA model was used to determine if the amount of course units students are enrolled in affected total time, quality and quality of time. The General Linear model was selected because the model was unbalanced; it was a mixed-effects model. The unit was random factor because the total number each student was enrolled in was randomly selected by each student; the project method was a fixed factor because the two methods were specifically selected for analysis.

The F-value is 2.57 and the p-value is $0.050 \geq 0.05$ for Unit, therefore we reject the null hypothesis thus there is a significant difference and the Unit factor does influence hours (total time). The $\mathrm{R}^{2}$ (adj) value indicates that $17.41 \%$ of the time the variation that occurs in dependent variable, hours, is reduced by the presence of both the Unit and Project Method factors.

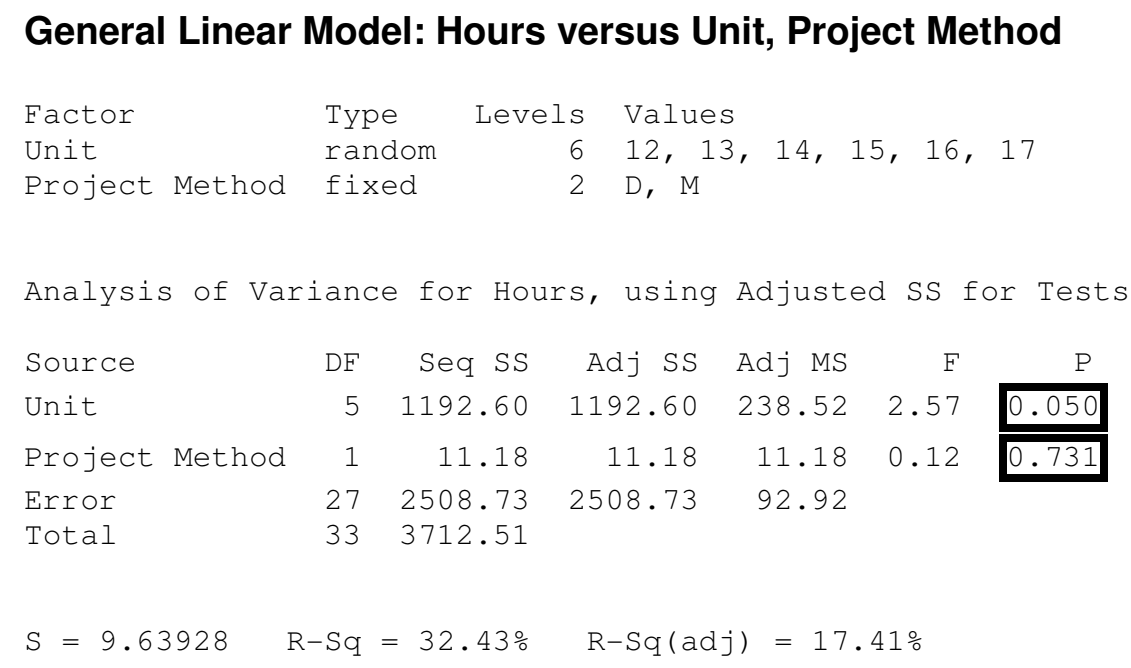


The F-value is 1.03 and the p-value is $0.420>0.05$ for Unit, therefore we fail to reject the null hypothesis thus there is no significant difference and the Unit factor does not influence score (quality). However, the $\mathrm{R}^{2}$ (adj) value, $0.00 \%$, indicates that variation in the model is poorly represented by the independent factors.

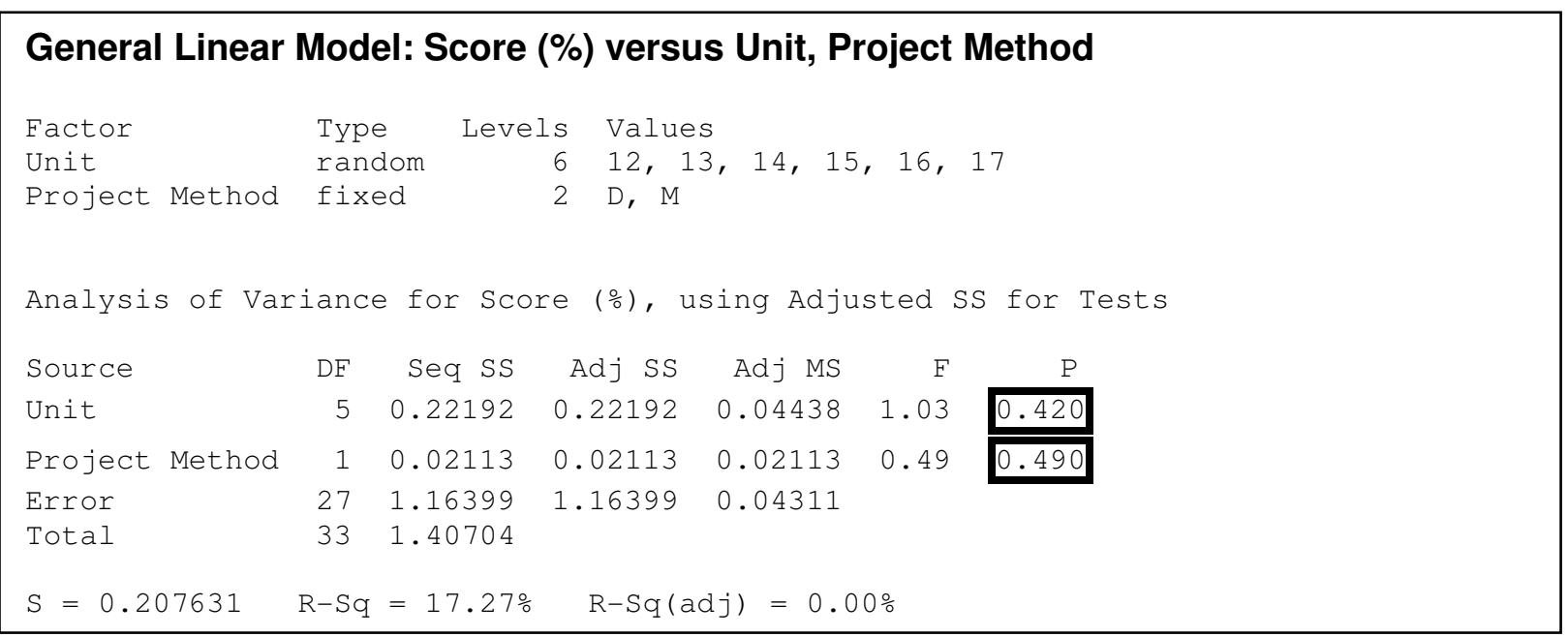

Figure 21: ANOVA for Score (\%) vs. Unit, Project Method

The F-value is 1.80 and the p-value is $0.148>0.05$ for Unit, therefore we fail to reject the null hypothesis thus there is no significant difference and the Unit factor does not influence Scr (\%)/ Hrs (quality of time). The $\mathrm{R}^{2}(\operatorname{adj})$ value indicates that $10.21 \%$ of the time the variation that occurs in dependent variable, hours, is reduced by the presence of both the Unit and Project Method factors.

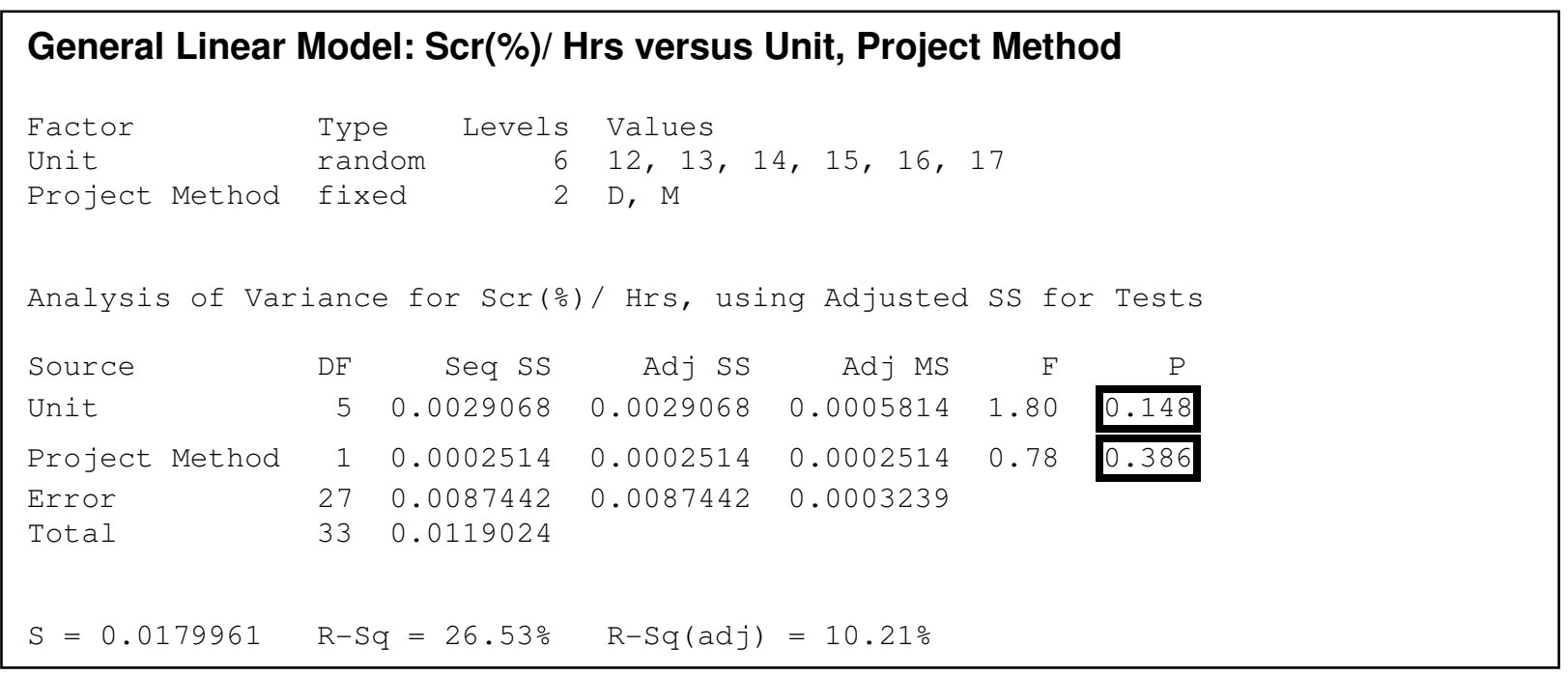

Figure 22: ANOVA for Score (\%)/ Hrs vs. Unit, Project Method 


\subsection{Discussion}

Although the results for the paired $t$ tests showed no significant difference for total hours, quality and quality of hours between critical path and critical chain project management the results yielded insight about the environmental conditions for this research.

For this experiment all the students completed and implemented the same project management method at the same time. The assumption was that the students had already learned and practiced the necessary skills and techniques to complete the projects, thus there would not be a steep learning curve from one project to the next. A more effective method would have been to assign half the students the critical path project management method and the other half the critical chain project management method for the first project then vice versa for the second. Alternating the project methodologies might eliminate any possible learning curve.

For this research it was evident through the statistical analysis that there was not a significant difference between MPM and DPM. However, a possible cause or source of error may have been caused by the nature of the course. The duration for each project may have been too short; hence the quick turn over rate for projects in the course does not require and is not conducive for the use of project management tools.

The students that participated in this experiment may not have previously been exposed to project management methods. IME 312 is one of several classes that consist of the junior level course series. The Project Organization and Management course (IME 303) introduces students to the theories and practices of project management and is also part of the junior series. If the students had not previously completed IME 303 or were not concurrently enrolled in the course then their first exposure to the project management methods and techniques occurred during the explanation for each project. 
This research was directed at determining if there was a significant difference between the MPM and DPM in the university environment, the results showed that there was a lack of significance. The university environment creates a unique situation for each operator/ student. The existence of midterms, students with part-time jobs and the student's individual learning ability can affect the results.

California Polytechnic State University, San Luis Obispo categorizes students as full-time if they are enrolled in twelve units per quarter; all of the students in this research were full-time. However, the variability within the units was not accounted for: professor instructing the course, course requirements and time required for the course.

\subsection{Conclusion}

This research aimed at determining if there was a significant difference between Milestone Project Management and Duration Project Management in a university environment. The concepts developed in the literature review led to the development of the modified critical chain method, Duration Project Management, which was implemented in the university experiment. The p-values that resulted from the paired $t$ test for each of the three measurements — total time, quality and quality of timerevealed that there was no significant difference between milestone and duration project management methodologies. The analysis also indicated that the number of units a student is enrolled in has an effect on the total hours spent on projects, but not quality or quality of time. However, further research is needed in the university environment to better understand the effects that MPM and DPM have on projects. 


\section{Chapter 6: Future Research}

The experiment conducted in this research was limited to one academic quarter, one course and students from one department. To further develop and provide more information on the effects of both critical path and critical chain project management in the university environment the experiment needs to be expanded.

The students who participated in this research are in the Industrial and Manufacturing Engineering Department at Cal Poly and part of their curriculum is project management. Expanding this research to other disciplines where project management is not included in their curriculum can provide insight to determine if being predisposed to project management affects the way a student completes a project versus those who have taken a project management course.

The course that was chosen for this research consisted of multiple projects within one academic quarter which allowed for repeated measurement analysis. A shortcoming in this research may have been caused by the course chosen to conduct the experiment because its requirements: multiple projects resulting in shorter project length. The shortened lengths may have not provided the necessary time for the techniques associated with each methodology to take hold and influence the project. In order to test this theory implementation of a project with alternative forms of measurement need to be conducted that include a course with a single quarter -long project and one with multiple projects thought the quarter.

If only one course is to be used as it was in this research, a yearlong study needs to be conducted in order to increase the sample size. At the California Polytechnic State University San Luis Obispo there are three academic quarter during the regular academic school year (September through June).

Conducting the same experiment in the same course throughout the school year will provide a larger sample size. These future experiments can help provide a better understanding on the effects that critical path and critical chain project management methodologies have in the university environment. 


\section{List of References}

Cerveny, J. F., \& Galup, S. D. (2002). Critical Chain Project Management Holistic Solution Aligning Quantitative and Qualitative Project Management Methods. Production and Inventory Management , 55-64.

Cui, N. W. (2010). Rescheduling After Inserting the Buffer in the Critical Chain Scheduling. International Conference on Logistics Systems and Intelligent Management (pp. 1105-1110). IEEE.

Goldratt, E. M. (1997). Critical Chain. Great Barrington, Ma: The North River Press Publishing Corporation.

Leach, L. P. (2005). Critical Chain Project Management 2nd Edition. Artech House.

Leach, L. P. (1999). Critical Chain Project Management Improves Project Performance. Project Management Journal , 39-51.

Lechler, T. G., Ronen, B., \& Stohr, E. A. (December 2005). Critical Chain: A New Project Management Paradigm or Old Wine in New Bottles? Engineering Management Journal , 45-58.

Levine, D. M., Ramsey, P. P., \& Smidt, R. K. (2001). Applied Statistics For Engineers and Scientist. Upper Saddle River, New Jersey: Prentice-Hall Inc.

Lipke, W. F. (2009). . "Prediction of Project Outcome. the Application of Statistical Methods to Earned Value Management and Earned Schedule Performance Indexes. International Journal of Project Management , 400-407.

Liu, J.-B. H.-H. (2008). Critical Chain Project Management Based Heuristic Algorithm Multiple Resourcesconstrained Project. International Seminar on Business and Information Management (pp. 330-335). IEEE.

Naeni, L. M. (2010). A Fuzzy Approach for the Earned Value Management. International Journal of Project Management .

Project Management Institute (PMI 1996). (1996). A Guide to the Project Management Body of Knowledge. Sylva, NC: PMI Inc.

Project Management Institute (PMI 2008). (2008). A Guide to the Project Management Body of Knowledge. Newton Square, Pa: PMI Inc.

Rezaie, K. B. (2009). Duration Estimation, a New Approach in Critical Chain Scheduling. 3rd Asia International Conference on Modelling and Simulation (pp. 481-484). AMS .

Rizzo, A. (2006). Lean Enterprise Project Management. Everett, Wa: Production Development Institute Train-The-Trainer Program. 
Robinson, H., \& Richards, R. (2009). Critical Chain Project Management: Motivation and Overview. IEEE Aerospace Conference Proceedings.

Steyn, H. (2000). An Investigation into the Fundamentals of Critical Chain Project Scheduling . International Journal of Project Management , 363-369.

Tian, Z. Z. (2010). A Critical Chain Based Multi-project Management Plan Scheduling Method. 2nd International Conference on Industrial and Information Systems (pp. 304-308). IEEE.

Zhau, Z. Y., You, W. Y., \& Zuo, J. (2010). Application of Innovative Critical Chain Method for Project Planning and Control Under Resource Constraints and Uncertainty. Construction Engineering and Management , 1056-1060. 


\section{Appendix A (Figures)}

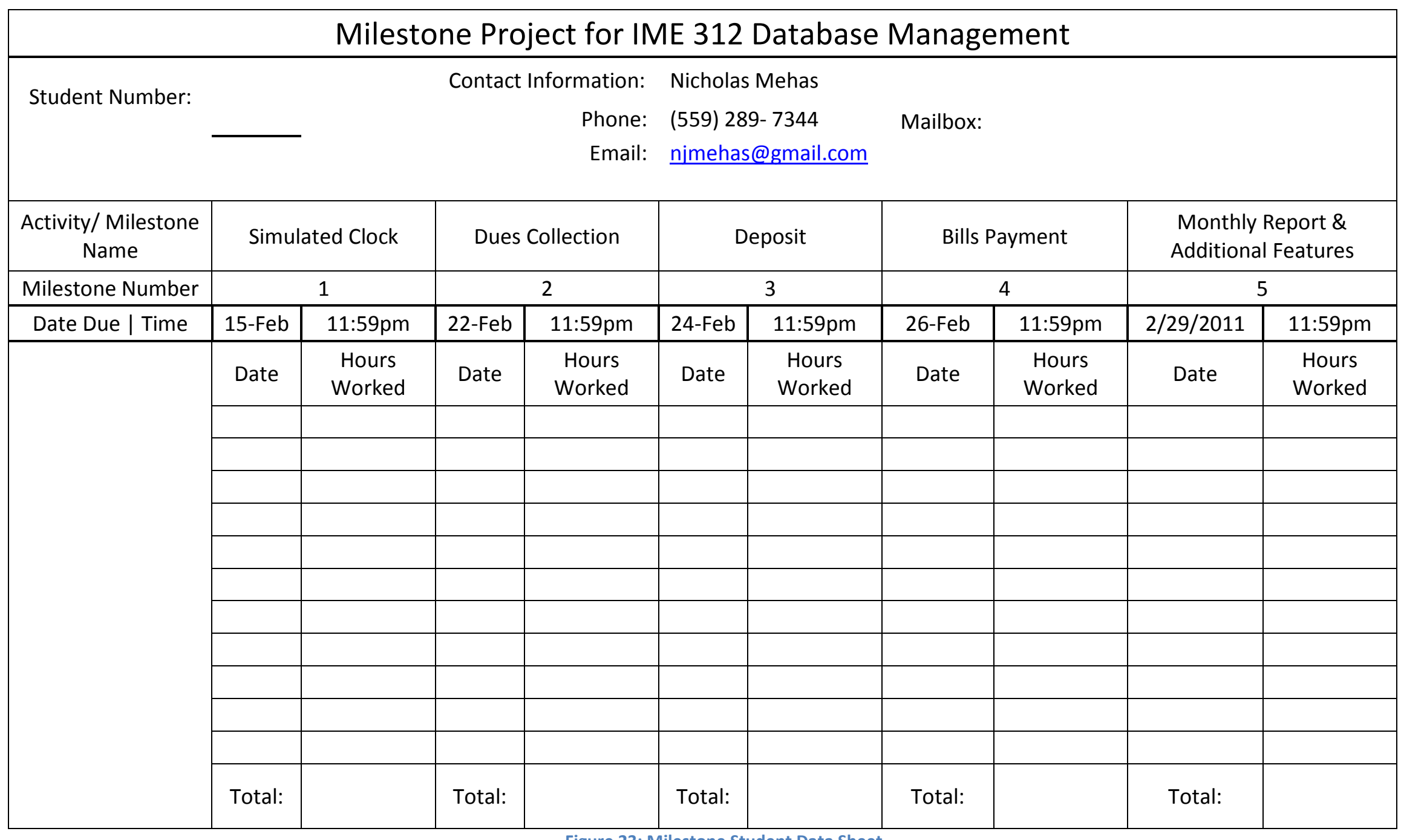

Figure 23: Milestone Student Data Sheet 


\begin{tabular}{|c|c|c|c|c|c|c|c|c|}
\hline \multicolumn{9}{|c|}{ Duration Project for IME 312 Database Management } \\
\hline \multirow{17}{*}{$\begin{array}{l}\text { Student } \\
\text { Number: }\end{array}$} & \multicolumn{4}{|c|}{ Contact Information: } & \multicolumn{2}{|c|}{ Nicholas Mehas } & \multirow{3}{*}{\multicolumn{2}{|c|}{ Mailbox: }} \\
\hline & & & & Phone: & \multirow{2}{*}{\multicolumn{2}{|c|}{$\begin{array}{l}\text { (559) 289- } 7344 \\
\text { njmehas@gmail.com }\end{array}$}} & & \\
\hline & & & \multicolumn{2}{|r|}{ Email: } & & & & \\
\hline & Date & Hours Worked & Date & Hours Worked & Date & Hours Worked & Date & Hours Workec \\
\hline & & & & & & & & \\
\hline & & & & & & & & \\
\hline & & & & & & & & \\
\hline & & & & & & & & \\
\hline & & & & & & & & \\
\hline & & & & & & & & \\
\hline & & & & & & & & \\
\hline & & & & & & & & \\
\hline & & & & & & & & \\
\hline & & & & & & & & \\
\hline & & & & & & & & \\
\hline & & & & & & & & \\
\hline & & & & & & & & \\
\hline Total & & & & & & & & \\
\hline
\end{tabular}

Figure 24: Duration Student Data Sheet 


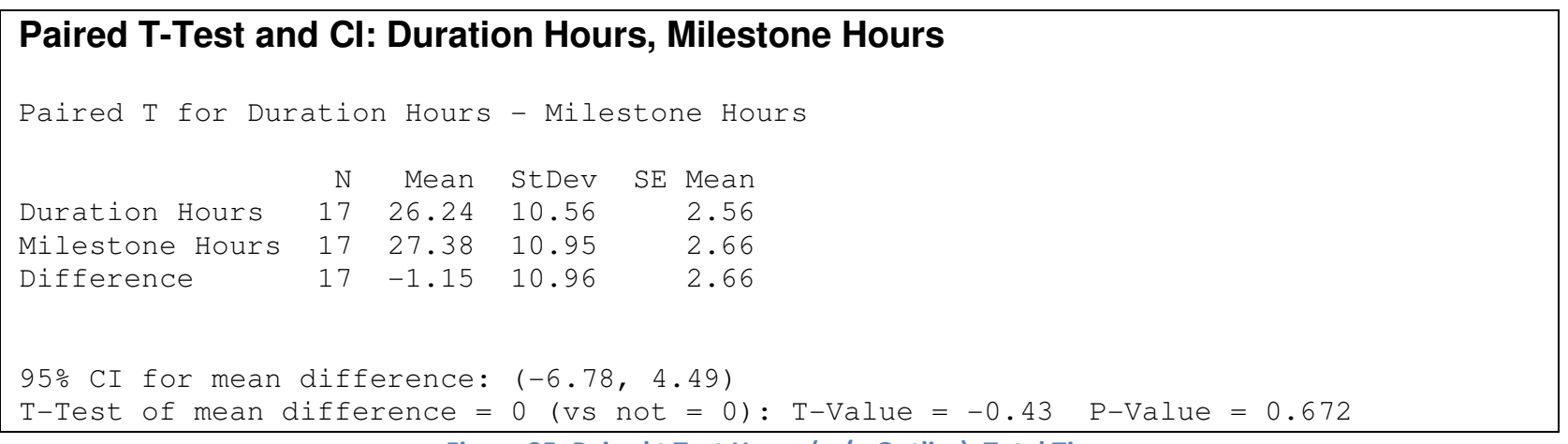

Figure 25: Paired t Test Hours (w/o Outlier), Total Time

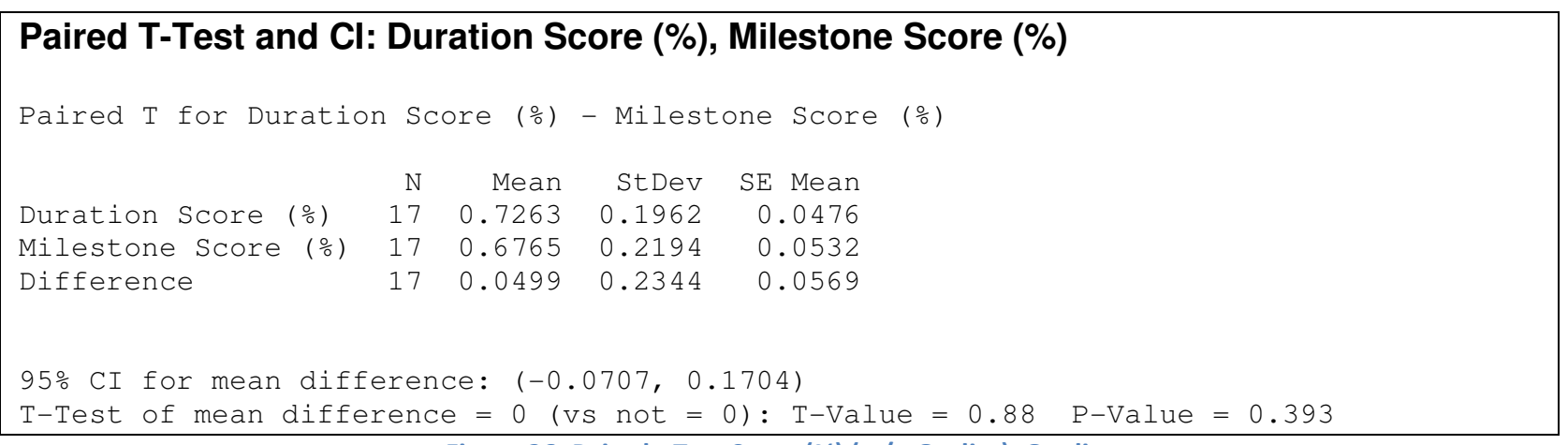

Figure 26: Paired t Test Score (\%) (w/o Outlier). Quality

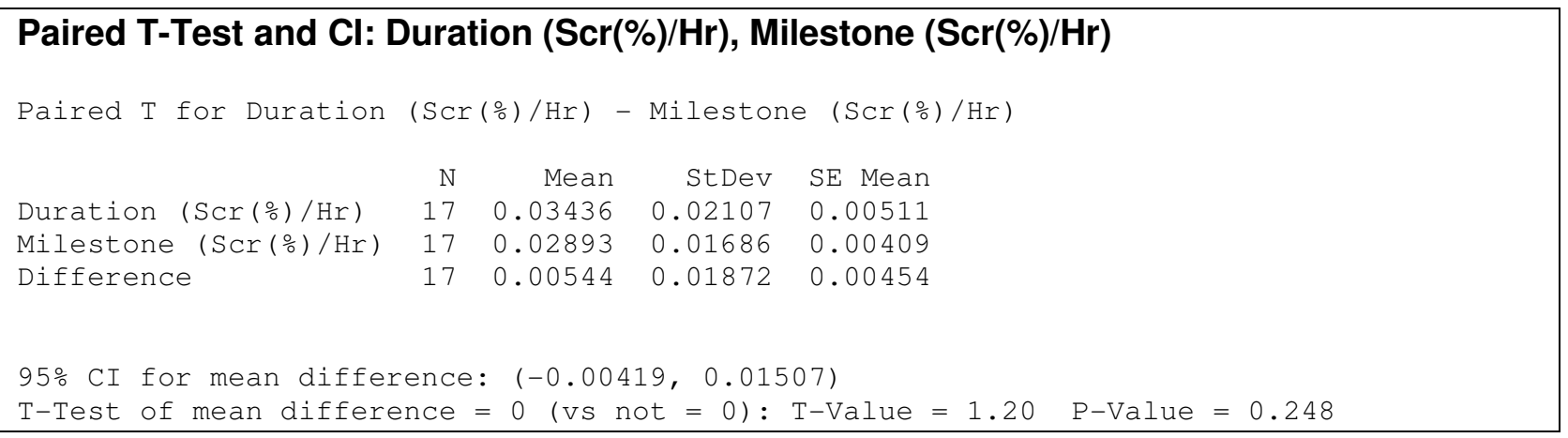

Figure 27: Paired t Test Score (\%)/ Hr (w/o Outlier), Quality of Time 


\section{Appendix B (Tables)}

\begin{tabular}{|c|c|c|c|c|c|c|c|c|c|c|c|c|}
\hline \multicolumn{13}{|c|}{ Milestone Project for IME 312 Database Management } \\
\hline Milestone Name & \multicolumn{2}{|c|}{ Simulated Clock } & \multicolumn{2}{|c|}{ Dues Collection } & \multicolumn{2}{|c|}{ Deposit } & \multicolumn{2}{|c|}{ Bills Payment } & \multicolumn{2}{|c|}{$\begin{array}{l}\text { Monthly Report \& } \\
\text { Additional Features }\end{array}$} & \multicolumn{2}{|c|}{ Individual Totals } \\
\hline Milestone Number & \multicolumn{2}{|c|}{1} & \multicolumn{2}{|c|}{2} & \multicolumn{2}{|c|}{3} & \multicolumn{2}{|c|}{4} & \multicolumn{2}{|c|}{5} & \multirow{3}{*}{ Hours } & \multirow{3}{*}{ Score } \\
\hline Date Due I Time & 16-Feb & Noon & 20-Feb & Noon & 21-Feb & Midnight & 22-Feb & Midnight & 24-Feb & Midnight & & \\
\hline Student Number & Hours & Score & Hours & Score & Hours & Score & Hours & Score & Hours & Score & & \\
\hline 1 & 0.25 & 10 & 2.5 & 145 & 3 & 40 & 3 & 40 & 4.25 & 40 & 13 & 275 \\
\hline 2 & 2 & 10 & 27 & 125 & 8 & 40 & 8 & 25 & 5 & 30 & 50 & 230 \\
\hline 3 & 1 & 5 & 13.5 & 85 & 4 & 40 & 3 & 5 & 2 & 10 & 23.5 & 145 \\
\hline 4 & 4 & 10 & 7 & 120 & 6 & 30 & 10 & 10 & 2 & 15 & 29 & 185 \\
\hline 5 & 1.5 & 10 & 10.25 & 135 & 10 & 30 & 11 & 20 & 11 & 40 & 43.75 & 235 \\
\hline 6 & 0.25 & 10 & 3 & 140 & 3 & 40 & 4.5 & 30 & 4.5 & 40 & 15.25 & 260 \\
\hline 7 & 0.25 & 10 & 18 & 85 & 18 & 30 & 5 & 40 & 9 & 45 & 50.25 & 210 \\
\hline 8 & 0.5 & 10 & 6 & 50 & 4 & 30 & 3 & 20 & 11 & 0 & 24.5 & 110 \\
\hline 10 & 1.5 & 10 & 13 & 150 & 5 & 30 & 6 & 35 & 4 & 50 & 29.5 & 275 \\
\hline 11 & 0.25 & 10 & 12 & 100 & 4 & 15 & 5 & 40 & 3 & 40 & 24.25 & 205 \\
\hline 13 & 1.5 & 10 & 5 & 150 & 2 & 30 & 3 & 40 & 11 & 35 & 22.5 & 265 \\
\hline 14 & 1 & 10 & 7 & 150 & 6 & 40 & 2 & 40 & 4 & 50 & 20 & 290 \\
\hline 15 & 1.5 & 10 & 10 & 20 & 8 & 30 & 3 & 30 & 0.5 & 30 & 23 & 120 \\
\hline 16 & 3 & 10 & 14 & 65 & 8 & 10 & 23 & 0 & 9 & 30 & 57 & 115 \\
\hline 17 & 1 & 10 & 10 & 90 & 3 & 40 & 2 & 0 & 2 & 40 & 18 & 180 \\
\hline 18 & 1 & 10 & 14 & 140 & 2 & 20 & 4 & 25 & 3 & 30 & 24 & 225 \\
\hline 20 & 0.5 & 10 & 12 & 95 & 4 & 20 & 2.5 & 15 & 5 & 45 & 24 & 185 \\
\hline 21 & 4 & 10 & 10 & 30 & 6 & 5 & 3 & 5 & 8 & 5 & 31 & 55 \\
\hline Total Points Possible & & 10 & & 150 & & 40 & & 40 & & 60 & & 300 \\
\hline Total & 25 & & 194.25 & & 104 & & 101 & & 98.25 & & 522.5 & 3565 \\
\hline
\end{tabular}




\begin{tabular}{|c|c|c|c|c|c|c|c|c|c|}
\hline \multicolumn{10}{|c|}{ Duration Project for IME 312 Database Management } \\
\hline Student Number & Hours & Score & & $\begin{array}{l}\text { Simulated } \\
\text { Calendar }\end{array}$ & $\begin{array}{c}\text { Student/ Faculty } \\
\text { Page }\end{array}$ & $\begin{array}{l}\text { Circulation Desk \& } \\
\text { Return Area }\end{array}$ & $\begin{array}{l}\text { Inventory } \\
\text { Auditing }\end{array}$ & $\begin{array}{l}\text { Director } \\
\text { Use }\end{array}$ & Total \\
\hline 1 & 20 & 175 & & 20 & 100 & 40 & 5 & 20 & 185 \\
\hline 2 & 30 & 165 & & 20 & 75 & 40 & 10 & 20 & 165 \\
\hline 3 & 33 & 110 & & 20 & 45 & 35 & 0 & 20 & 120 \\
\hline 4 & 22 & 75 & & 20 & 30 & 5 & 0 & 20 & 75 \\
\hline 5 & 35 & 140 & & 20 & 80 & 5 & 5 & 30 & 140 \\
\hline 6 & 8 & 110 & & 0 & 65 & 20 & 10 & 10 & 105 \\
\hline 7 & 35 & 210 & & 20 & 90 & 40 & 10 & 30 & 190 \\
\hline 8 & 25 & 140 & & 20 & 65 & 40 & 0 & 25 & 150 \\
\hline 10 & 40 & 195 & & 20 & 100 & 30 & 5 & 30 & 185 \\
\hline 11 & 14 & 155 & & 20 & 55 & 40 & 10 & 20 & 145 \\
\hline 13 & 10 & 185 & & 20 & 55 & 40 & 10 & 40 & 165 \\
\hline 14 & 16 & 125 & & 0 & 90 & 33 & 2 & 0 & 125 \\
\hline 15 & 30 & 150 & & 0 & 90 & 30 & 10 & 30 & 160 \\
\hline 16 & 6 & 155 & & 0 & 85 & 40 & 10 & 20 & 155 \\
\hline 17 & 35 & 163 & & 20 & 98 & 40 & 10 & 0 & 168 \\
\hline 18 & 35 & 185 & & 20 & 90 & 30 & 5 & 30 & 175 \\
\hline 20 & 17 & 220 & & 20 & 100 & 40 & 10 & 25 & 195 \\
\hline 21 & 41 & 90 & & 20 & 25 & 30 & 10 & 5 & 90 \\
\hline Total Possible Points & & 210 & Total & 20 & 100 & 40 & 10 & 40 & 210 \\
\hline
\end{tabular}




\begin{tabular}{|c|c|c|c|c|}
\hline $\begin{array}{l}\text { Project } \\
\text { Method }\end{array}$ & Unit & $\begin{array}{c}\text { Score } \\
(\%)\end{array}$ & Hours & Scr(\%)/ Hrs \\
\hline $\mathrm{D}$ & 16 & 0.83 & 20 & 0.0417 \\
\hline $\mathrm{D}$ & 14 & 0.79 & 30 & 0.0262 \\
\hline$D$ & 16 & 0.52 & 33 & 0.0159 \\
\hline $\mathrm{D}$ & 12 & 0.36 & 22 & 0.0162 \\
\hline $\mathrm{D}$ & 17 & 0.67 & 35 & 0.0190 \\
\hline $\mathrm{D}$ & 16 & 0.52 & 8 & 0.0655 \\
\hline $\mathrm{D}$ & 13 & 1.00 & 35 & 0.0286 \\
\hline $\mathrm{D}$ & 12 & 0.67 & 25 & 0.0267 \\
\hline $\mathrm{D}$ & 15 & 0.93 & 40 & 0.0232 \\
\hline $\mathrm{D}$ & 12 & 0.74 & 14 & 0.0527 \\
\hline $\mathrm{D}$ & 16 & 0.88 & 10 & 0.0881 \\
\hline $\mathrm{D}$ & 14 & 0.60 & 16 & 0.0372 \\
\hline $\mathrm{D}$ & 15 & 0.71 & 30 & 0.0238 \\
\hline $\mathrm{D}$ & 12 & 0.78 & 35 & 0.0222 \\
\hline $\mathrm{D}$ & 16 & 0.88 & 35 & 0.0252 \\
\hline $\mathrm{D}$ & 17 & 1.05 & 17 & 0.0616 \\
\hline $\mathrm{D}$ & 14 & 0.43 & 41 & 0.0105 \\
\hline M & 16 & 0.92 & 13 & 0.0705 \\
\hline $\mathrm{M}$ & 14 & 0.77 & 50 & 0.0153 \\
\hline $\mathrm{M}$ & 16 & 0.48 & 23.5 & 0.0206 \\
\hline $\mathrm{M}$ & 12 & 0.62 & 29 & 0.0213 \\
\hline $\mathrm{M}$ & 17 & 0.78 & 43.75 & 0.0179 \\
\hline$M$ & 16 & 0.87 & 15.25 & 0.0568 \\
\hline$M$ & 13 & 0.70 & 50.25 & 0.0139 \\
\hline $\mathrm{M}$ & 12 & 0.37 & 24.5 & 0.0150 \\
\hline $\mathrm{M}$ & 15 & 0.92 & 29.5 & 0.0311 \\
\hline $\mathrm{M}$ & 12 & 0.68 & 24.25 & 0.0282 \\
\hline $\mathrm{M}$ & 16 & 0.88 & 22.5 & 0.0393 \\
\hline$M$ & 14 & 0.97 & 20 & 0.0483 \\
\hline $\mathrm{M}$ & 15 & 0.40 & 23 & 0.0174 \\
\hline $\mathrm{M}$ & 12 & 0.60 & 18 & 0.0333 \\
\hline $\mathrm{M}$ & 16 & 0.75 & 24 & 0.0313 \\
\hline $\mathrm{M}$ & 17 & 0.62 & 24 & 0.0257 \\
\hline$M$ & 14 & 0.18 & 31 & 0.0059 \\
\hline
\end{tabular}




\begin{tabular}{|r|r|r|r|}
\hline \multicolumn{1}{|c|}{ Units } & $\begin{array}{c}\text { Hours Diff } \\
\text { (Dur - Mile) }\end{array}$ & $\begin{array}{c}\text { Scr \% Diff } \\
\text { (Dur - Mile) }\end{array}$ & $\begin{array}{c}\text { Scr(\%)/Hr Diff } \\
\text { (Dur - Mile) }\end{array}$ \\
\hline 16 & 7 & -0.083 & -0.029 \\
\hline 14 & -20 & 0.019 & 0.011 \\
\hline 16 & 9.5 & 0.040 & -0.005 \\
\hline 12 & -7 & -0.260 & -0.005 \\
\hline 17 & -8.75 & -0.117 & 0.001 \\
\hline 16 & -7.25 & -0.343 & 0.009 \\
\hline 13 & -15.25 & 0.300 & 0.015 \\
\hline 12 & 0.5 & 0.300 & 0.012 \\
\hline 15 & 10.5 & 0.012 & -0.008 \\
\hline 12 & -10.25 & 0.055 & 0.025 \\
\hline 16 & -12.5 & -0.002 & 0.049 \\
\hline 14 & -4 & -0.371 & -0.011 \\
\hline 15 & 7 & 0.314 & 0.006 \\
\hline 12 & 17 & 0.176 & -0.011 \\
\hline 16 & 11 & 0.131 & -0.006 \\
\hline 17 & -7 & 0.431 & 0.036 \\
\hline 14 & 10 & 0.245 & 0.005 \\
\hline
\end{tabular}

Table 6: $\mu_{D}$ Data for Total Time, Quality and Quality of Time \& Units

\begin{tabular}{|r|r|}
\hline $\begin{array}{c}\text { Duration Score } \\
\text { (\%) }\end{array}$ & $\begin{array}{c}\text { Milestone Score } \\
\text { (\%) }\end{array}$ \\
\hline 0.8333 & 0.9167 \\
\hline 0.7857 & 0.7667 \\
\hline 0.5238 & 0.4833 \\
\hline 0.3571 & 0.6167 \\
\hline 0.6667 & 0.7833 \\
\hline 0.5238 & 0.8667 \\
\hline 1.0000 & 0.7000 \\
\hline 0.6667 & 0.3667 \\
\hline 0.9286 & 0.9167 \\
\hline 0.7381 & 0.6833 \\
\hline 0.8810 & 0.8833 \\
\hline 0.5952 & 0.9667 \\
\hline 0.7143 & 0.4000 \\
\hline 0.7762 & 0.6000 \\
\hline 0.8810 & 0.7500 \\
\hline 1.0476 & 0.6167 \\
\hline 0.4286 & 0.1833 \\
\hline
\end{tabular}

Table 7: Quality (Score \%) Data 